\title{
RELATIVE SPECTRAL TRANSMISSION OF THE ATMOSPHERE
}

\author{
By Enoch Karrer and E. P. T. Tyndall
}

\section{CONTENTS}

Page

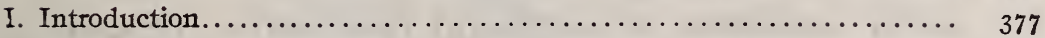

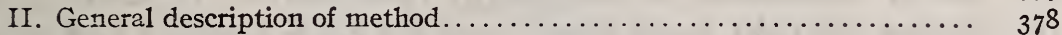

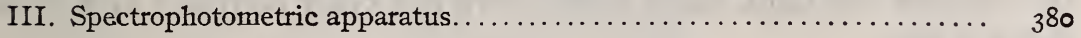

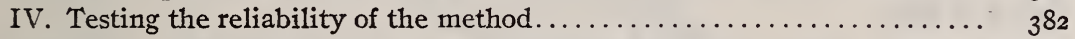

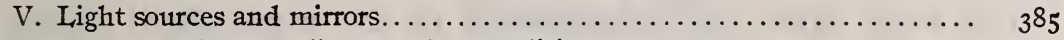

VI. Apparatus for recording weather conditions............... 388

VII. Incidental and miscellaneous methods tried $\ldots \ldots \ldots \ldots \ldots \ldots \ldots \ldots \ldots . \quad 3^{89}$

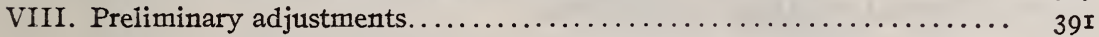

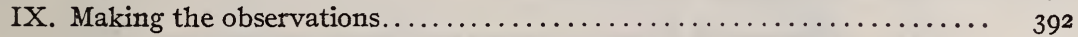

X. Reduction of observations. . . . . . . . . . 393

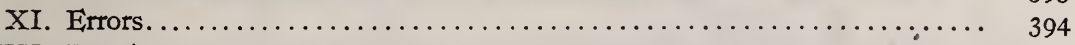

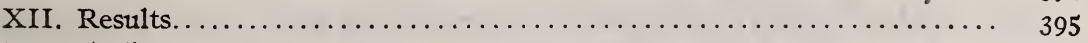

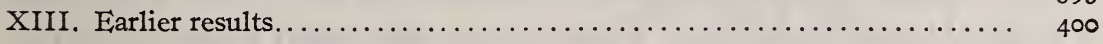

XIV. Synopsis of weather conditions..................... 403

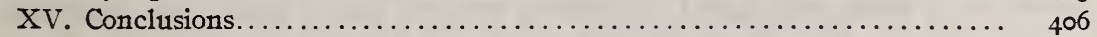

XVI. General application of the data...................... 407

\section{INTRODUCTION}

The subject of the transmission of light through the atmosphere has always received considerable attention in astrophysics. Its great importance there lies in connection with the determination of the rate of reception of energy by the earth from the sun.

The subject has, however, an intimate relationship to aerial photography, and, furthermore, has great importance in connection with the use of light projectors (I) for automobile and locomotive headlamps; (2) for signaling and as beacons; and (3) for searching on land, on water, and in the air. Little attention seems to have been given to the latter aspects up to recent years.

A knowledge of the transmission of the atmosphere is essential to a satisfactory comparison of search lamps whose characteristics have been observed under different atmospheric conditions, and is also essential to an intelligent consideration of the question, What color should the searchlight beam have to give best results? 
In the first case the transmission data for mixed light only are in general required, but, because searchlight beams differ greatly in color, the transmission data for colored light are at times very desirable. In the second case, however, the transmission for monochromatic light throughout the spectrum is demanded.

In both cases there should be data available for all weather conditions. For the first, absolute values of the transmission are essential; for the latter, relative values will suffice. To obtain the relative spectral transmission of the atmosphere is one phase of the problem of the color of the searchlight beam. This problem also involves a knowledge of how the contrast sensibility of the eye, under conditions of searchlight illumination, depends upon the color of the field, both when there is a color contrast and when there is not.

The work upon the transmission of the atmosphere which is reported here relates to the relative spectral transmission under a few different weather conditions.

\section{GENERAL DESCRIPTION OF METHOD}

The method finally adopted to secure the data may be stated in general terms as follows: Light from a lamp near a spectrophotometer was reflected from a distant mirror back into the spectrophotometer. The intensity of the beam from the distant mirror, after traversing the intervening atmosphere twice, was compared wave length for wave length with a beam directly from the lamp. Relative values were thus obtained for the relative transmission of light by the atmosphere throughout the visible spectrum. Certain necessary corrections were applied to the observed values, as will be described later. The use of the distant mirror was resorted to for the reason that it minimized the equipment and number of operators. The distance from the mirror to the spectrophotometer was $600 \mathrm{~m}$. The nature of the intervening terrain may be seen in Fig. I, an aerial photograph taken by Dr. S. M. Burka. The light source and spectrophotometer are indicated by $S$, the distant mirror by $D$, and the near mirror by $N$. A portion of the path over which the beam passed lay over a ravine with dense woods and foliage, through which ran a brook. The more distant part of the path lay over vacant and unimproved city lots, and was also nearer the ground. Fig. 2 is an approximate vertical section of the country traversed by the light, showing these portions together with approximate height above sea level. 
Scientific Papers of the Bureau of Standards, Vol. 16

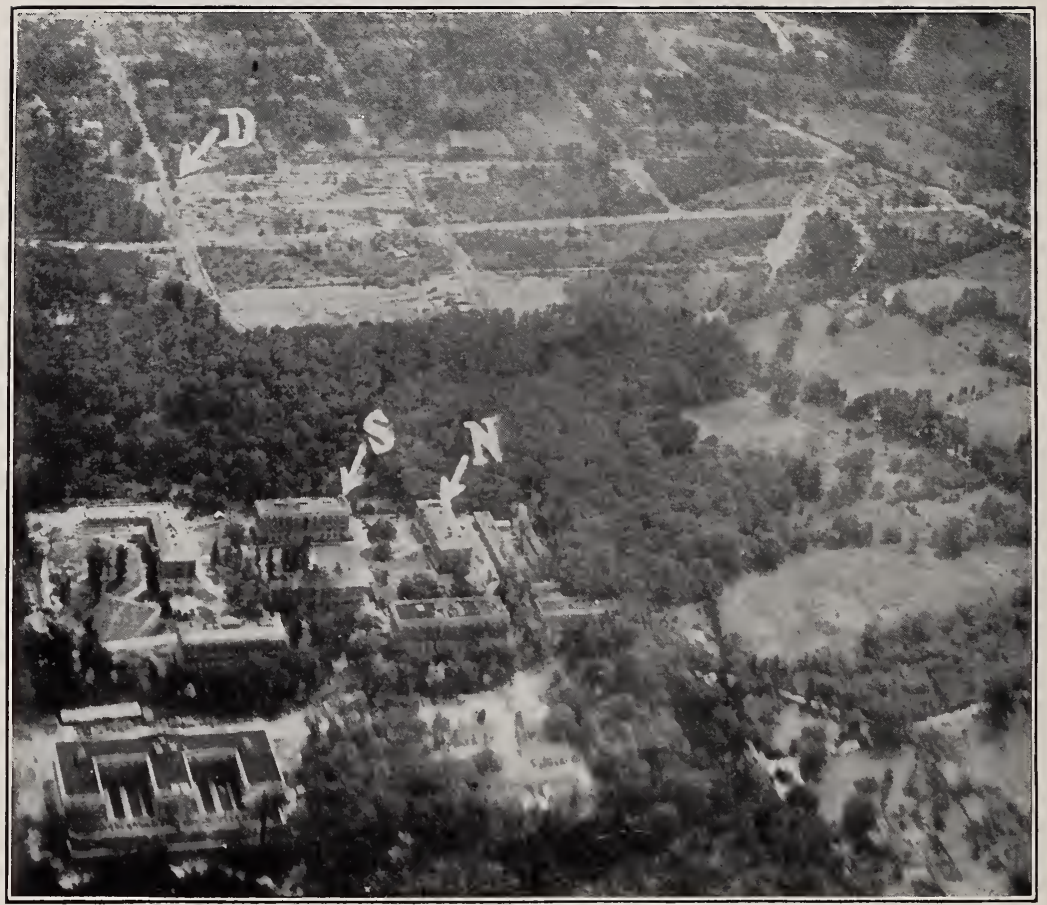

FIG. I.-Bird's-eye view of terrain, showing position of near mirror $N$, distant mirror $D$, light source and spectrophotometer $S$ 


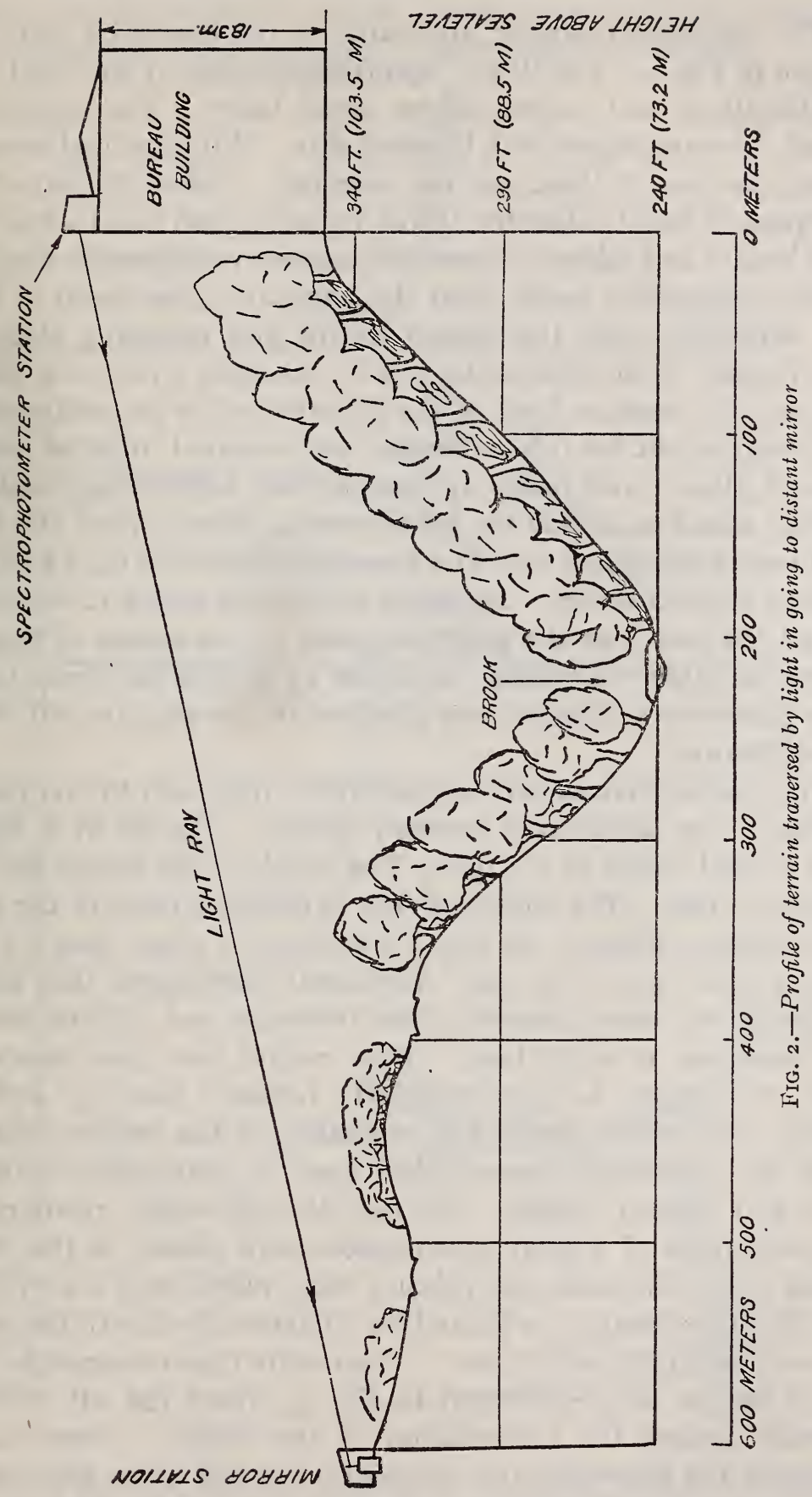




\section{SPECTROPHOTOMETRIC APPARATUS}

The spectrophotometric apparatus in the observing station is shown in Fig. 3. The Brace ${ }^{1}$ spectrophotometer $A$ was used with modifications and accessories as noted below. The collimators 3 and 7 were equipped with bilateral slits. With the final arrangement, the first of these was not essential. Before the slit of the comparison field (collimator 7 ) was a ground glass 8 and a mirror 9 . The lens $I O$ and mirror $I I$ were also necessary elements in the path of the comparison beam from the lamp $I 2$. The beam of light $a b$, impinging upon the distant mirror and returning along $c d$, was focused by an achromatic lens 6 -diameter $6 \mathrm{~cm}$, focal length $54 \mathrm{~cm}$-at a point in front of the slit attached to the collimator 3 . The limiting slit for this collimator was mounted, together with a ground glass 4 and prism 5, upon a small table which could be readily raised to enable the beam coming directly from the lamp $I 2$ to enter the slit, or could be lowered to allow the light from the distant mirror to enter. An image of the light source $I 2$ was formed by the lens 6 at the point occupied by the center of this slit when the table was raised. A screen 13 limited the direct beam. The photometric balance was obtained by varying the slit width of collimator 7 .

The spectrophotometer was calibrated from 400 to $700 \mathrm{~m} \mu$ by means of the helium and mercury spectra. The slit at 4, Fig. 3, had a fixed width of $0.2 \mathrm{~mm}$. The width of the ocular slit was about $0.2 \mathrm{~mm}$. The widths of slits in different parts of the spectrum were as follows: At 700, 7.3 $\mathrm{m} \mu$; 600, $4.5 \mathrm{~m} \mu$; 500, $2.4 \mathrm{~m} \mu$; $420, \mathrm{I} .2 \mathrm{~m} \mu ; 546,3.35 \mathrm{~m} \mu$. Additional diaphragms (not shown in the figure) were inserted in the telescope and collimators for the exclusion of stray light. Very careful tests were made for such stray light, for proportionality between intensity and slit width, and finally also of the reliability of the results obtained with the spectrophotometer when used in conjunction with the lens and distant mirror. To test the slit-width relationship, sectored discs of known transmission were placed in the direct beam $I_{2}-I_{3}$, the table and prism 5 being raised, and the width of the slit on collimator 7 adjusted for a balance, first with the sector in, and, secondly, with it out. The results thus obtained for two wave lengths are represented in Fig. 4, where the slit width is plotted against the transmission of the sectors. These curves intersect the slit-width axis between 0.015 and $0.020 \mathrm{~mm}$, as has

1 Astrophys. Jour. 11, pp. 6-24; 1900. 
been found by others. ${ }^{2}$ The width used for most of the observations was not less than $0.3 \mathrm{~mm}$, so that there could be no appreciable departure from the direct proportionality assumed.

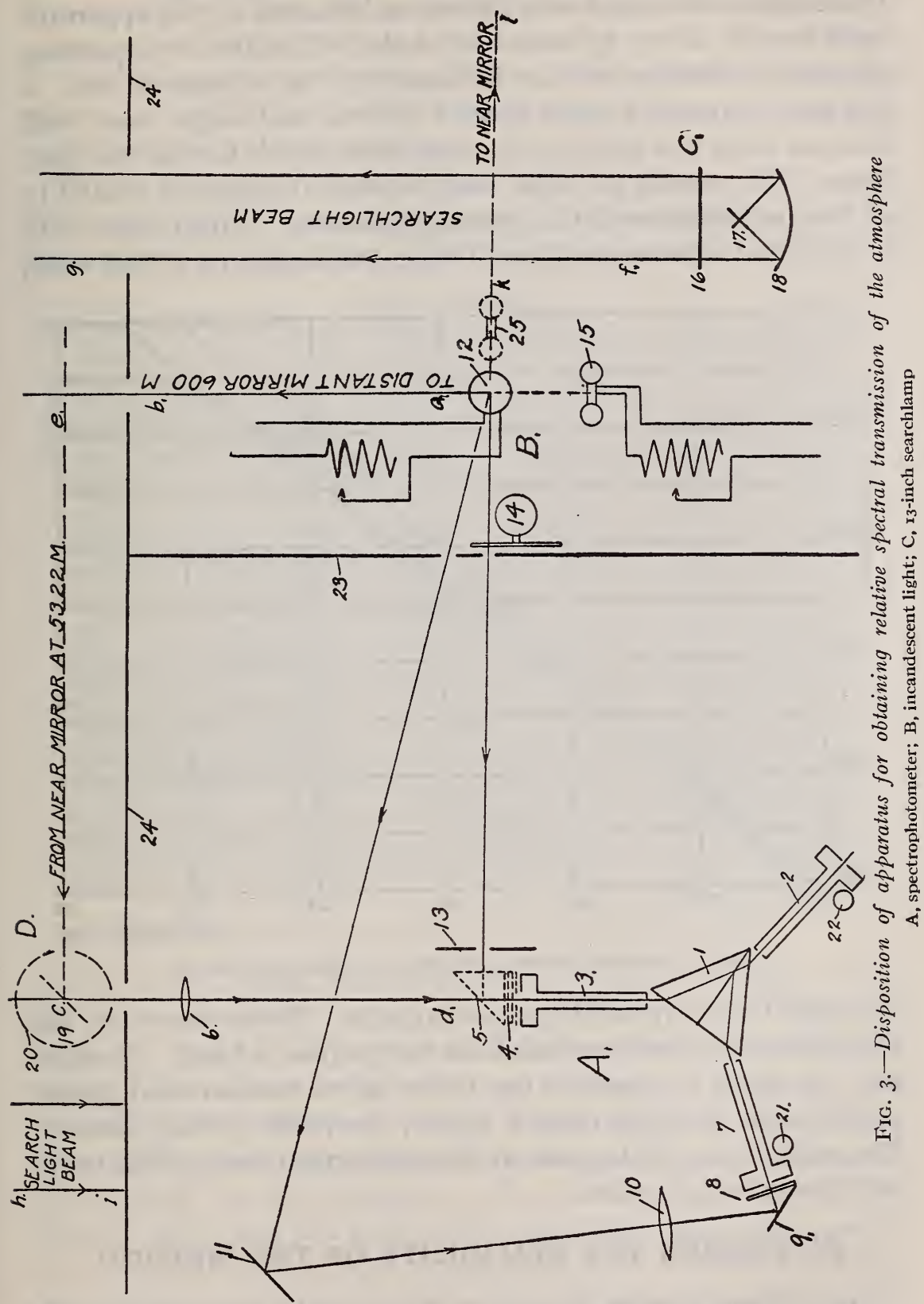

To test for the effect of stray light, carefully calibrated colored glasses were inserted in the direct beam in place of the sectored 
discs above. The transmission of these glasses had been carefully measured by several methods ${ }^{3}$ and was very accurately known. The results of these observations are shown in Fig. 5, where the transmission of several such glasses, as indicated by the apparatus used here, is shown by dots and circles, while the corresponding accurately known values are indicated by the full-line curves. A red color screen for wave lengths $660 \mathrm{~m} \mu$ and longer was used, because there was considerable stray light in this part of the spectrum. The results of these tests showed the general reliability of the performance of the spectrophotometer. Much more data of this kind were accumulated during the beginning of the work,

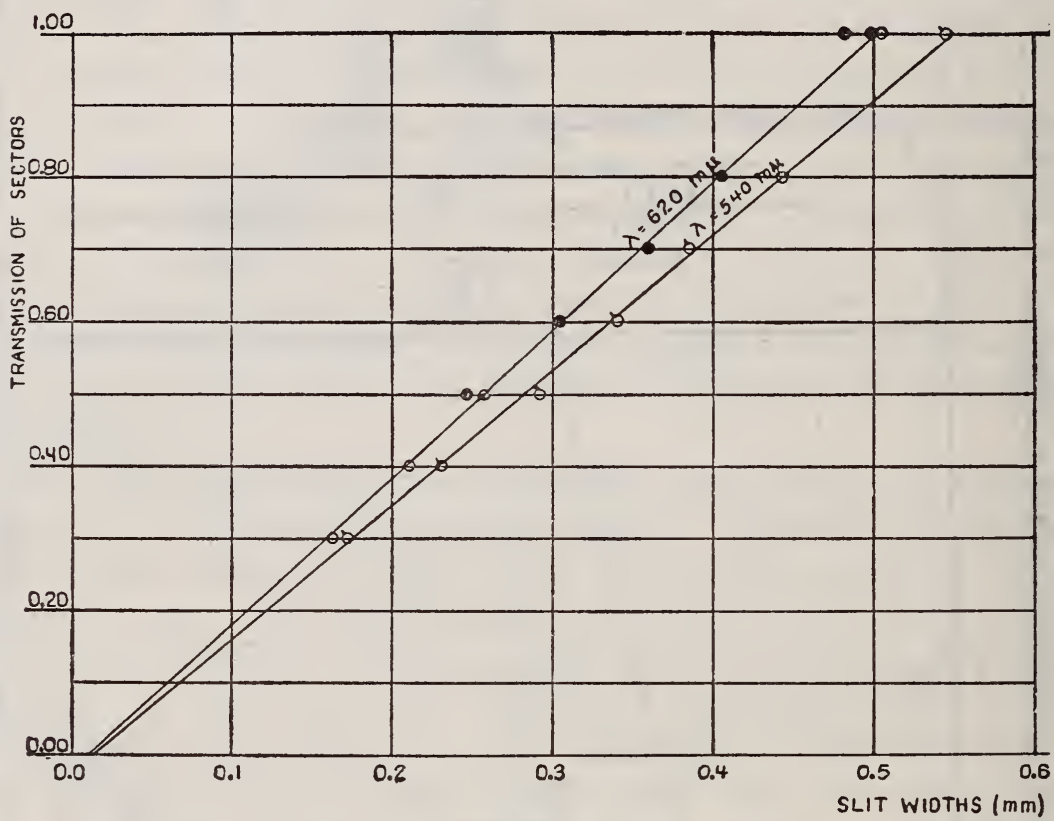

FIG. 4.-Relation between slit width and sector transmission

of which the curves of Fig. 5 are typical. These show that the slit widths used were permissible for the purpose in hand. Another test was made by inserting one of the above standardized glasses in the beam from the distant mirror, the prism 5 being lowered. The transmission of the glass so obtained agreed very satisfactorily with the standard values.

\section{TESTING THE RELIABILITY OF THE METHOD}

Tests of the general reliability of the results obtained by this method were made by using another mirror stationed nearby, 
which thus gave an image of light source $I 2$ through a practically negligible thickness of atmosphere. Reference to Fig. 3 will show the relative disposition of the apparatus for this test. A beam of light $k l$ impinged upon a mirror at $53.2 \mathrm{~m}$ distant and returned, $e c$, to be reflected by a similar mirror 19 through the lens 6 into the spectrophotometer. Thus, after reflection from the mirror I9, the path of the light from the near station was identical with that from the distant station.

This near station was on the roof of a neighboring building of approximately the same height as the roof upon which the spectrophotometer was stationed. Between these two buildings is a

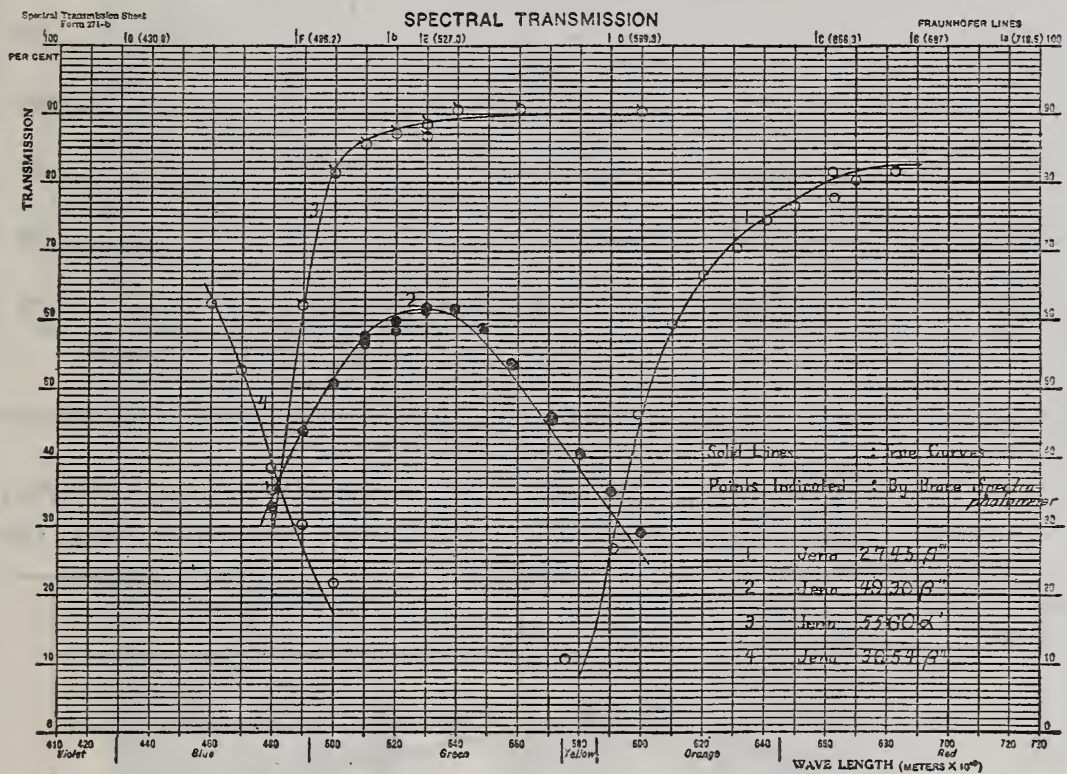

FIG. 5.-Test of spectrophotometer by transmission standards

stretch of dry, sandy ground used for parking automobiles. (See Fig. 6, an aerial view of the Bureau buildings used, taken by Dr. S. M. Burka.) It is important to bear this in mind in interpreting some of the results obtained for the near station. The atmosphere was undoubtedly full of dust particles during the time these observations were made. This was noticed also while some observations ${ }^{4}$ on the intensity and on the polarization of the diffused light along the path of the searchlight beam were made. It is evident that if the intervening atmosphere were nonabsorbing the apparent transmission obtained by the use of the near station 


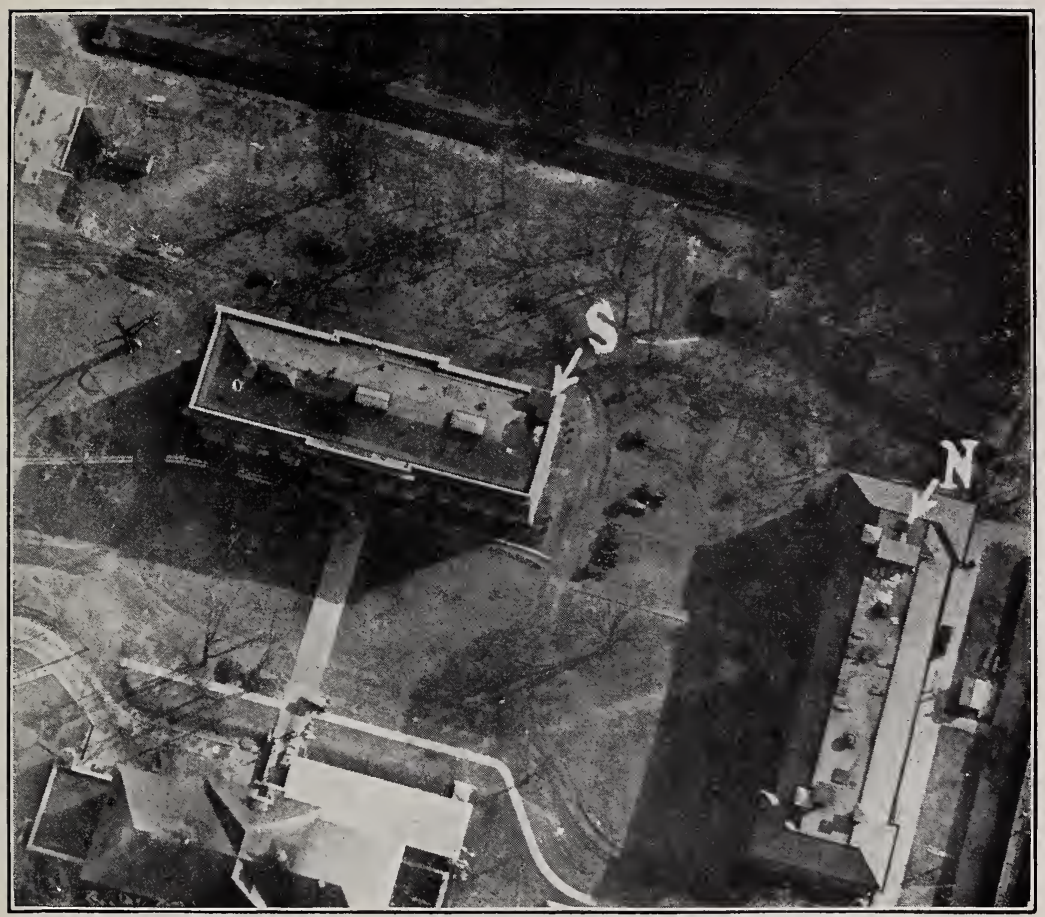

FIG. 6.-An aerial view showing the near mirror station $N$ and the observing station $S$, containing spectrophotometer and light source 
should be identical throughout the spectrum with the relative reflectivity of the two mirrors used represented in curve 5 of Fig. 7. In order, however, to make this test under conditions as

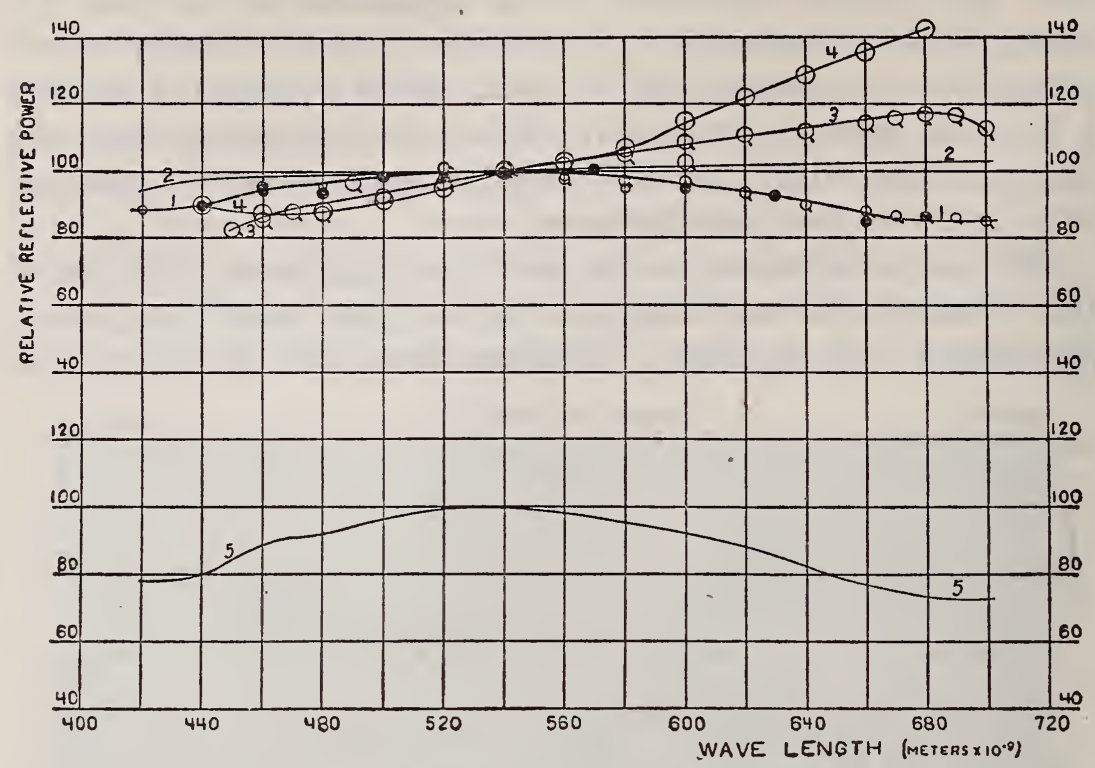

FIG 7.-Relative reflecting power of mirrors

No. I, range-finder mirror; No. 2, freshly silvered flat; No. 3, slightly tarnished flat; No. 4, very tarnished flat; No. 5, two range-finder mirrors

nearly as possible identical with those when the distant mirror is used, the near mirror must be sufficiently far away that the

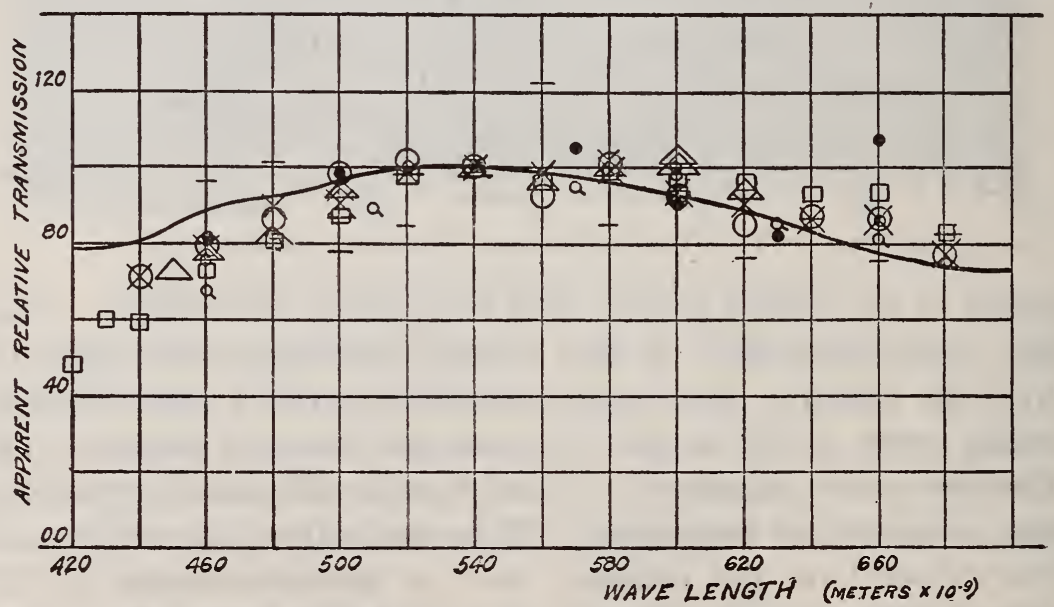

FiG. 8.-Test of reliability of the method by use of near station

Full line: Reflecting power of two range-finder mirrors. Points indicated: Observed relative transmission uncorrected for reflection of mirrors

image of the light source formed by the lens 6, Fig. 3, is approximately of the same dimensions as that when the distant mirror is used. The results of this test are represented in Fig. 8, con- 
sisting of seven sets of observations taken on the nights of May $I_{3}$ and $1_{4}, 1_{4}$ and $1_{5}, 15$ and 16,19 and 20, 22 and 23,26 and 27 , 27 and 28 , I919. The observations corresponding, respectively, to these dates are dots, hooked circles, dashes, triangles, circles, squares, and crosses. The full-line curve taken from Fig. 7 is that of the relative refiection for the two mirrors used. The data of May. I5 and 16, represented by dashes, are very scattered on account of some mist in the atmosphere that night and some smoke carried by a north wind from the near-by power house. This set is inserted merely to show the extremely erratic effects of polluted atmospheres and should not be considered in forming a judgment of the results. There is in all the rest some indication of absorption and scattering in the atmosphere between the two stations, in that all the sets show definitely a somewhat higher relative transmission in the red than in the blue region. From the remarks made above with reference to the nature of the intervening ground these differences in relative transmission are readily explained, so it may be concluded that the test does prove the method to be reliable.

The near station was also to be used to determine the transmission of very dense fogs, for the use of the distant station under these conditions was not entirely satisfactory, it being impossible to obtain a field of sufficient brightness in the spectrophotometer. The corrections discussed in detail below, applied to the observations obtained with the near station, are precisely similar to those made for the distant mirror. A number of curves showing the changes in transmission at $540 \mathrm{~m} \mu$ during the night are shown in Fig. 9. When observations were made as late as 5:30 a. m., as indicated by these curves, it was assured by test that the daylight entering the spectrophotometer was negligible. A general characterization of the weather conditions on the nights of the above dates are as follows: May I3 and I4, overcast but clear; May I4 and 15 , clear; May 15 and 16 , fine mist at 2 a. m.; May 19 and 20, clear; May 22 and 23, clear, becoming somewhat misty at 2 a. m.; May 26 and 27, clear; May 28 and 29, clear, the beam of light, however, showed clearly marked diffusion effects.

\section{LIGHT SOURCES AND MIRRORS}

Throughout the observations with the near station a $500-$ watt stereopticon lamp was used, with a sector of less than $10^{\circ}$ in the beam from the mirror. 
The light source in the earlier observations with the distant station was a 50o-watt, type C, stereopticon lamp. Later the vacuum tungsten arc, known as the Point-o-lite, was used, and finally a rooo-watt tubular projection lamp. The last was distinctly the most satisfactory, chiefly on account of the increased intensity. A few observations were made with a 5oo-watt lamp

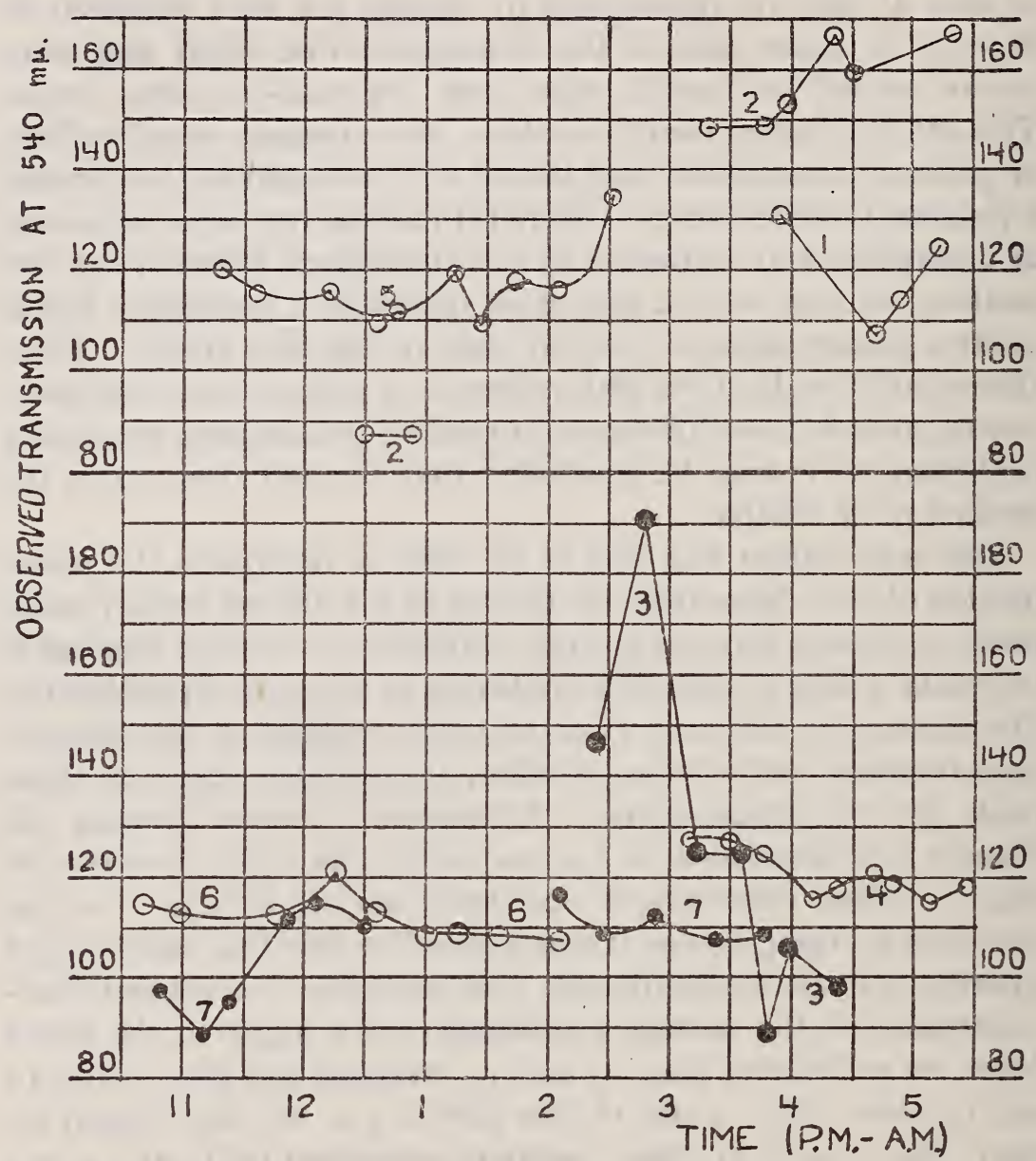

FIG. 9.-Change of observed transmission at $540 \mathrm{m \mu}$ while the observations of Fig. 8 were being made

No. I, May I3-I4; No. 2, May I4-I5; No. 3, May I5-I6; No. 4, May I9-20; No. 5, May 22-23; No. 6, May 26-27; No. 7, May $27-28$

with half of its bulb silvered. This method of increasing the intensity would have been satisfactory if the silvering had been permanent. The Point-o-lite was not intense enough and deteriorated rapidly. A small mercury arc was also used, as will be described later. The chief qualification of a light source for this work should be to furnish a beam of light of as great intensity as 
possible in the direction of the mirror. The source itself may be to advantage quite large in its vertical dimension. In the horizontal dimension the source must be restricted, for the diameter of the image formed by the lens 6 , Fig. 3 , is the effective slit width, which it is desirable to keep as narrow as is practicable.

The distant mirror was mounted upon a standard, as shown in Fig. Io. The mirror 5 was secured against a plate of aluminum 4 which could be tilted forward and backward by virtue of the hinge 7 . The tilting was controlled by the spring 9 and the screw 10. Gross movements of the mirror about the vertical axis could be made by releasing the clamping screw I4. Finer adjustments were made by means of the screw II and the spring 12 , after securing the screw I3. For all observations made after April 28, the mirror and mount were secured to a concrete pier $I$.

A commercial plateglass mirror was used in preliminary trials and found very unsatisfactory. At a distance of $600 \mathrm{~m}$ several images of the light source could be seen. This made it difficult to judge when the mirror was adjusted and also caused

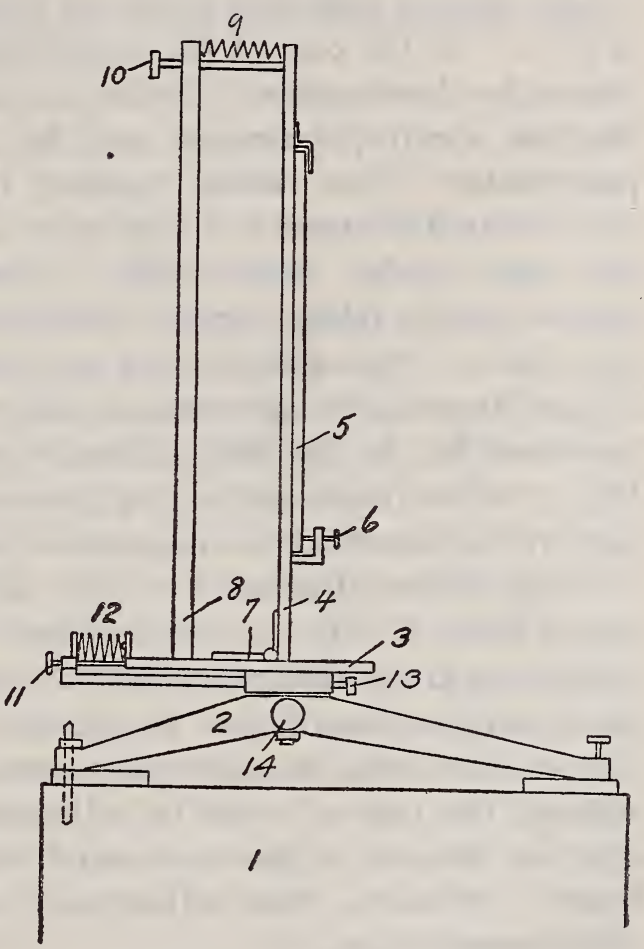

FIG. Io.-Mirror and mounting at distant station very irregular effects on slight movements of the mirror. Mirrors made from optical flats silvered on the front surface were suggested. Such a flat of plate glass $(2.5 \mathrm{~cm}$ thick and $25 \mathrm{~cm}$ diameter) was secured from the optical shop of the Bureau, and another flat $(2.5$ $\mathrm{cm}$ by $30 \mathrm{~cm}$ ) was loaned by R. W. Porter for this purpose. Both of these were true planes to within one-quarter wave length across the entire surface. Trials with the smaller flat proved to be satisfactory in all respects, except that it tarnished very readily. Considerable preliminary data and some reported below were obtained with it. Because of the uncertainty arising from the 
decreasing reflecting power of the tarnishing surface, however, a portion of a mirror from a range finder used in military aeronautics was tried. This mirror, made by W. H. Taylor, of this Bureau, was silvered on the back, since its surfaces were very closely plane parallel. Although it was found to be slightly cylindrical (having a vertical generatrix), it proved extremely satisfactory, no dispersion effects being noticeable. Most of the data with the distant station and all of the data with the near station were obtained with it.

The relative reflecting power of these mirrors was determined (Fig. 7). In the case of the range-finder mirror this was accomplished by three methods: By the Brace spectrophotometer, KönigMartens spectrophotometer, and by the photoelectric spectrophotometer. $^{5}$ The values obtained by each of these methods are indicated in curve $I$ of Fig. 7 by the dots, the hooked circles, and plain circles, respectively. Values of the freshly silvered optical flat are taken from the Smithsonian Physical Tables, page 198; 1916. The values for the very tarnished flat were obtained by the Brace spectrophotometer, curve 4, Fig. 7; for the slightly tarnished flat, by the König-Martens spectrophotometer, curve 3, Fig. 7. The relative reflecting power of two range-finder mirrors used at the near station is represented by curve 5 of Fig. 7 .

To facilitate adjustment of the distant mirror, a small navy search lamp $C$, Fig. 3, was mounted in an adjoining room and trained upon the distant mirror. Since the path of the reflected beam could be clearly seen by the observer near the spectrophotometer, who was in telephonic communication with the distant station, the mirror could be adjusted approximately in a few minutes, whereas without the search lamp it might be a matter of hours. Of course, final adjustment was always made with the incandescent lamp.

\section{APPARATUS FOR RECORDING WEATHER CONDITIONS}

To record the meteorological factors the following pieces of auxiliary apparatus were employed: (I) Psychrometer, Assmann type, which was read at frequent intervals while observations were being made. This instrument, although in good condition, did not record saturation values at times even when the air had evidently become saturated. (2) A barograph, which gave a continuous record of the atmospheric pressure. (3) A rain gage, 
consisting of a graduated burette and a funnel of $\mathrm{I} 3 \mathrm{~cm}$ diameter. This was read at frequent intervals during the rains. (4) A "fog meter," which was used to determine the average value of the amount of water suspended in the air during misty and foggy weather. This fog meter consisted of a $U$-tube filled with calcium chloride, through which was drawn a quantity of air measured by a dry gas meter. Since no observations on a foggy atmosphere were made, the study of the performance of the fog meter, as well as the calibration of it, have been deferred.

\section{INCIDENTAL AND MISCELLANEOUS METHODS TRIED}

It is deemed worth while to mention in a general way some other methods which were tried, but which did not prove feasible. The chief failure in all other methods is that a sufficient amount of illumination can not be obtained in the photometric field. On account of the very high intensity of the search lamps, one might imagine this to be the ideal source. The flickering in the arc, however, and the changing color of the light in different directions are very objectionable features. Various attempts were made to use a ground glass in front of the collimator 3 , Fig. 3, since the use of such a glass in front of a permanent slit on the collimator would have been superior in many ways to the method finally adopted. By using a lens to focus the light on such a glass, a sufficiently bright field was obtained with a I3inch 20-ampere search lamp, but the variations that constantly occur in the arc and the uncertainty in the composition of the direct beam and comparison beam prevented the adoption of this source. Several attempts were made to use incandescent lamps at the focus of various parabolic reflectors, but all were abandoned, either because of lack of intensity or because of the filaments not being sufficiently concentrated. Images of the filaments were always formed, and any one of these might fall upon the slit so that slight movements of either the distant mirror or of the near reflector would cause great uncertainties by introducing independent changes in the direct and comparison beams. At the time such reflectors were tried, however, the distant mirror was not mounted upon a concrete pier. It is possible that with the mirror secured to a concrete pier reflectors might give better results.

The mercury arc lamp affords a convenient means of obtaining several monochromatic beams without the use of a spectropho- 
tometer when suitable screens ${ }^{6}$ are used to isolate the particular wave lengths desired. A quartz mercury lamp was allowed to illuminate the distant mirror, and an image of it was formed at the observing station by means of a 4 -inch telescope objective. These images were sufficiently bright when viewed through the color screens, but were ill formed, apparently owing to errors in the objective. Although not much time was devoted to constructing suitable apparatus for this method, it is well to give a brief description of the set-up in which the mercury lamp (quartz, 220 volts) was used. The lamp was placed approximately at the focus of a search-lamp mirror $(35.5 \mathrm{~cm}$ diameter, about $6 \mathrm{I} \mathrm{cm}$ focus). The beam reflected from the distant mirror was focused in a cavity of a magnesium carbonate block, and this in turn illuminated the photometric field (Lummer-Brodhun cube) viewed through a low-power eyepiece. The purpose of the carbonate block was to obtain a uniform field by diffusing the light from the image, and also to eliminate, so far as possible, the flickering effect. To maintain the color match, a similar hollow magnesium carbonate block was placed in the comparison beam. It was hoped to use this auxiliary photometer to make, at several wave lengths of the mercury spectrum, observations which would serve to check or furnish a basis for correcting the observations made simultaneously with the spectrophotometer, and possibly also to give an absolute value of the transmission at some one wave length. It was found, however, that the changes in the spectrophotometer were of a different nature from those occurring in the auxiliary photometer. Also, since various modifications would have been necessary before absolute values could be obtained by this means, such observations were discontinued. The method actually used to correct the readings on the spectrophotometer for variations due to instrumental shifts and to weather changes is described below.

To avoid the varying effects of tarnishing of the optical flat, it was reversed so that the reflection took place at the silver-glass surface. However, because of a slight lack of parallelism of the two faces of the flat, such marked dispersion effects were introduced that this plan was abandoned.

Instead of varying the intensity by varying the slit width, Nicol prisms were tried in the comparison beam. However, those available were of small aperture, and even if they had not 
been, it was concluded that the reduction of intensity would be too great for satisfactory observation.

Several attempts were made to use the Martens polarization photometer with the mercury arc as a check on the spectrophotometer, the direct light from the lamp being focused, on return from the distant mirror, onto the slit of the photometer. This was abandoned on account of the great loss of intensity and because of the sensitiveness to shifts.

Time and space did not permit trying one method which might have been used as a very valuable check. This is the rotatory dispersion photometer as described by Priest, ${ }^{7}$ which could have been used either with mercury light and suitable color screens to give relative transmissions at certain isolated wave lengths, or with an incandescent source to measure the color difference between the light which had traversed the atmosphere and that which had not.

\section{PRELIMINARY ADJUSTMENTS}

Before taking data there were always a number of preliminary adjustments to be made. The calibration of the spectrophotometer was checked at $546 \mathrm{~m} \mu$ by means of the mercury lamp in position 25, Fig. 3. Because of poor mechanical construction of this particular instrument, such checking and adjustment of the spectrophotometer was necessary every night. The general position of the distant mirror was noted by the use of the searchlight beam, and, if necessary, adjustments were made to bring the reflected beam to its correct position. After the mirror was mounted on the concrete pier, the reflected beam retained its position for weeks at a time. It was also necessary to adjust the lens 6, Fig. 3. The use of such a lens to form an image of a distant source is an adaptation of the method described by Brace ${ }^{8}$ for stellar spectrophotometry. In this method the small image serves as a slit and should therefore occupy the same position as the center of the slit used for the direct beam. Any deviation to one side of this position introduces a relative displacement (color difference with incandescent source) of the two parts of the photometric field.

To obtain the correct adjustment, the small mercury lamp ${ }_{5}$, Fig. 3, was used, and the lens 6 set so that the image was formed directly in front of the wide-open slit of the collimator 3 .

7 Phys. Rev. (2), 9, p. 34x; x9x 7.

${ }^{8}$ Astrophys. Jour., 11, pp. 6-24; 1900 .

$183257^{\circ}-20-3$ 
Then having set the wave-length scale to correspond with one of the monochromatic images of the lamp (say at $546 \mathrm{~m} \mu$ ), the lens 6 was adjusted to bring that image to the center and in the plane of the ocular slit, as judged with the aid of the ocular lens by the absence of parallax between the slit and image. When one image was in place, the other images of the mercury lamp were also correctly adjusted. The collimator 7 was adjusted to bring the image of its slit into coincidence with the ocular slit. Since any shifting of the spectrophotometer, the lens 6 , or the distant mirror would spoil this adjustment, repeated checks were made on the position of the green image. Using the incandescent source, a perfect color match in all parts of the spectrum was obtained in the field of the spectrophotometer, when the green image of the mercury lamp was in the correct place. The lens 6 was carried by a microscope mount which permitted linear displacement along both the vertical and the horizontal, and permitted rotation about a horizontal axis, and slight but sufficient rotation about a vertical axis.

The intensity of the comparison beam-that is, beam illuminating the slit of the collimator 7-was adjusted until a slit width of about $0.40 \mathrm{~mm}$ was required to balance that of the distant beam in the middle of the spectrum $(540 \mathrm{~m} \mu)$. The intensity also of the direct beam from the lamp 12, Fig. 3 , was adjusted by means of sectored disks until it was balanced by about the same slit width. These adjustments of the approximately equal slit widths and equal intensities gave, so far as they could be adhered to, added assurance of the correct proportionality for the slits.

\section{MAKING THE OBSERVATIONS}

As shown in Fig. 3, the spectrophotometer and the light sources were in separate rooms. The photometer room was completely dark, with the exception of the illumination from the two small apertures in the partition wall and the small light necessary for reading the slit width and recording the observations. The observer was protected from even this small amount of light by a black curtain hung from the ceiling, which shut him off completely from the rest of the room. However, it was necessary for him to set the wave-length scale, which was illuminated by a miniature 2-volt lamp, but this was so shielded that no direct light from it passed into his eyes. This complete protection from outside light enabled readings to be made with fields of far lower intensity 
than would otherwise have been possible. The readings of the slit width on the collimator 7 , the recording of observations, the manipulation of prism and slit before the collimator 3 , the reading of weather instruments, etc., were all done by the other operator.

After the preliminary adjustments mentioned above had been made, observations could be commenced. The data to be recorded were (I) weather observations, (2) spectrophotometer settings as follows: A set at $540 \mathrm{~m} \mu$, followed by two other points in the spectrum, each $20 \mathrm{~m} \mu$ from the preceding, then another at $540 \mathrm{~m} \mu$. A check on the position of the $546 \mathrm{~m} \mu$ image of the mercury lamp was taken at this time, and if it was still in correct adjustment two more points each at $20 \mathrm{~m} \mu$ from the preceding point were taken. But if the image was not in the center of the ocular slit, the lens 6 , Fig. 3 , was readjusted and the $540 \mathrm{~m} \mu$ reading repeated before proceeding to the next point in the spectrum. In this manner the whole visible spectrum was gone through. The exact procedure in obtaining observations at any one wave length was as follows: Two settings of the slit on the collimator 7 to balance the field from the distant mirror were made (the prism, ground glass, and lens being lowered), followed by either one or two on the direct beam (prism, ground glass, and slit raised). This was continued until Io settings had been made on the distant beam and 5 or Io on the direct beam. The average slit width necessary to balance the distant beam was divided by the average slit width necessary to balance the direct beam and this quotient designated as the observed transmission.

\section{REDUCTION OF OBSERVATIONS}

Several corrections had to be applied to the observed transmission in order to obtain the true relative transmission. The method was as follows: (I) The observed transmission at $540 \mathrm{~m} \mu$ was plotted against time. Such curves were at times very irregular, for they indicated not only the actual changes due to weather but also those due to instrumental shifts. (2) To reduce the values for the other wave lengths to what they would have been had the transmission at $540 \mathrm{~m} \mu$, as observed in the spectrophotometer, remained constant, the observations at all other wave lengths were corrected according to these curves for $540 \mathrm{~m} \mu$. In making these corrections it is assumed, of course, that the changes in weather conditions and in the spectrophotometer would affect all wave lengths alike. A justification for this assumption is found 
in the fact that when the observed transmission at $540 \mathrm{~m} \mu$ remained constant throughout one complete set of observations, the curve obtained for the relative transmission was similar to those obtained when large corrections had to be made. In the former case, of course, little or no correcting had to be done. (3) A correction was then applied for the relative reflecting power of the mirror. (4) The final values were then plotted in terms of that at $540 \mathrm{~m} \mu$, arbitrarily assigning a value of 100 to the relative transmission at this point.

\section{ERRORS}

A few general remarks upon the errors involved in the method may be made at this point, though it has already been pointed out where such errors are likely to occur.

I. ERrors Due to Shifting of The Mirror.-Any great shift in the position of the mirror caused a corresponding change in the position of the image formed by the lens 6 . The effect of this has been discussed in explaining the necessary adjustments of the lens.

2. Errors Due to Variation in the Light Source.-The variations due to change in voltage across the incandescent lamp produced no changes in the apparent transmission. This was one of the excellent features of the method used. The voltage across the lamp was that of the general lighting line.

3. Errors Due to Instrumental Shifts.-Possible errors due to this cause are very large. It has been described above, however, how precautions were taken to detect such shifts and to eliminate them by using the observed transmission at one point $(540 \mathrm{~m} \mu)$ as a standard in terms of which to express values at the other points. Much of the irregularity that occurred in the observed transmission at $540 \mathrm{~m} \mu$ must be attributed to shift in the instrument, at least in those curves where checking with the mercury lamp showed that the green image $(546 \mathrm{~m} \mu)$ had changed. In cases where the green image had not changed, and yet the observed transmission at $540 \mathrm{~m} \mu$ varied rather erratically, the cause was not quite clear. These changes were at times very abrupt and peculiar.

4. ERrors Due to Moisture on Optical Parts.-Moisture on the surfaces of optical parts in the immediate neighborhood of the spectrophotometer could seldom appear on account of the temperature difference between the observing room and the 
outside. Only on one occasion was moisture found on the spectrophotometer prism. Deposition of moisture upon the distant mirror would have been serious, but it was found that the shed housing the mirror was sufficient guarantee against it happening. The mirror was inspected each morning at the end of the observations. While the optical flat was in use attempts were made to keep the surface of the mirror free from moisture, either by heating the shed or by directing an air current against the mirror. Heating was not permissible because of the great amount of flickering which was produced in the photometric field. The operation of a fan was detrimental because of mechanical disturbances. At that time, however, the concrete pier had not been installed. When all sorts of weather conditions are encountered at different seasons of the year, it will probably be necessary to maintain the mirror housing at a slightly higher temperature than its surroundings.

5. ERrors Due to Changes iN WeAther Conditions.-It has been noted above how a record of the changes due to weather conditions was obtained by frequent observations at $540 \mathrm{~m} \mu$, thus making it possible to apply approximate corrections, but corrections for sudden changes in the weather could never be made with entire satisfaction. Under such conditions an acceptable value can be obtained only by making a large number of observations. Some of the observed variations were undoubtedly due to the formation of mist in the valley and not to general weather changes. Clouds of mist could sometimes be seen rising out of the valley over the tree tops into the path of the beam. The greater portion of the path of the beam was above or just at the upper surface of the layers of fog and mist quite frequently seen in the early hours of the morning.

6. ERrors Due to Flickering IN THE Photometric Field.The flickering in the field, due to the twinkling effect of the distant light source, was frequently a cause of great annoyance, but it could not be eliminated. The use of a larger lens would tend to eliminate the effect of the flickering by taking in a larger portion of the wave front. The flickering was greatest on the clearest nights.

\section{RESULTS}

The most reliable data were those obtained after the distant mirror was mounted on a concrete pier, and for most of these the 
range-finder mirror was used. They are in part plotted in Fig. II, curves 3 to 8 , the observations having been made on the nights of May 5 and 8, inclusive, and May I2. Curves $I$ and 2 are from observations with the silvered optical flat made on April 28 and 29. The silver had tarnished considerably, but its reflecting power was determined after the run on April 30 (curve 4, Fig. 7). These observations of curve 4 were the first obtained after mounting the mirror on the pier. They are considered to be as reliable as those obtained with the range-finder mirror. The earlier data obtained before the construction of the pier, and before certain refinements of methods had been adopted, are not so reliable. They will be discussed later.

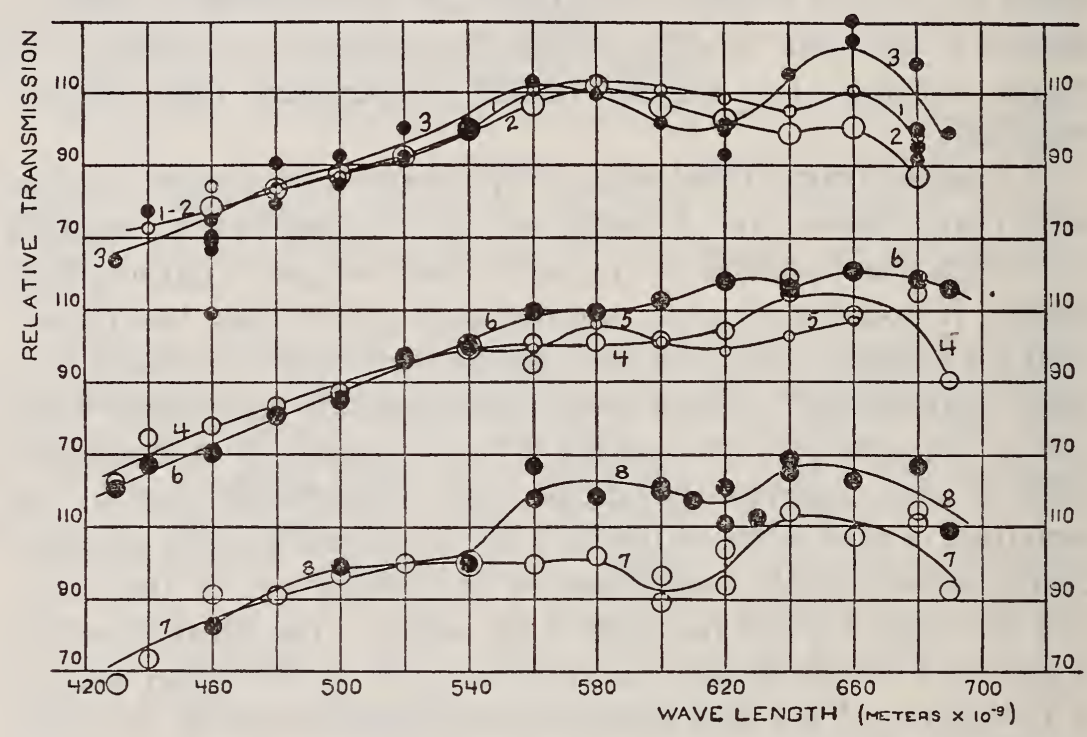

FIG. Ir.-Relative transmission of atmosphere; generally overcast and high humidity No. I, Apr. 25-29; No. 2, Apr. 29-30; No. 3, May 5-6; No. 4, May 6-7; No. 5, May 6-7, second run; No. 6, May 7-8; No. 7 , May I $2-I_{3} ;$ No. 8, May I2-13, second run

For the curves shown in Fig. II, the weather conditions may be described as being generally overcast and characterized by high humidity. The curves are identical, within experimental errors, for wave lengths less than $540 \mathrm{~m} \mu$, and shows that the transmission uniformly decreases with the wave length. From 540 to $690 \mathrm{~m} \mu$ they are all of the same general type, presenting an interesting depression in the region of 590 to $640 \mathrm{~m} \mu$, with a minimum at about 6 ro $\mathrm{m} \mu$, and a subsequent rise with a maximum near $660 \mathrm{~m} \mu$. From 660 to $690 \mathrm{~m} \mu$ there is in all cases a decrease in relative transmission. In certain instances, notably curves 3,7 , and 8 , the maxima and minima are very pronounced. In others, 
such as curves 4 and 6 , the minimum at 6 ro $\mathrm{m} \mu$ is less clearly defined. The observations for 3,7 , and 8 were made after a fine drizzle; those for 4 and 6 were made after light showers in the early hours of the night. Curve 5 pertains to the same night as curve 4 ; the data, however, were obtained after $\mathrm{I}: 45$ a. m., when the drizzle had ceased and the atmosphere apparently had cleared entirely.

Other data which were obtained with the range-finder mirror mounted on the pier are given in curves $I, 2$, and 3, Fig. I2. These may be classed with the data just presented, so far as relia-

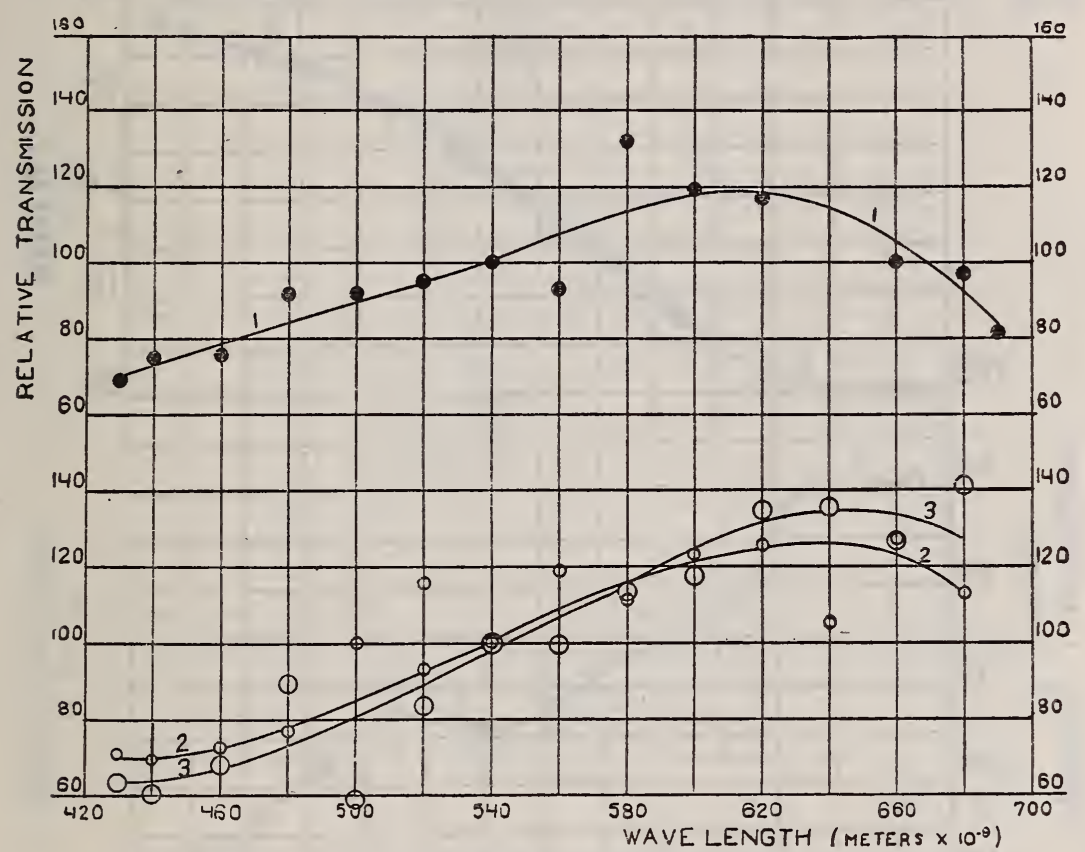

FIG. I2.-Relative transmission of atmosphere; generally rainy

No. r, May 6-7; Nos. 2 and 3 , May 8-9, first and second runs

bility goes. For these, the condition of the weather may be described as generally rainy. The curves have a slope from 540 to $430 \mathrm{~m} \mu$, almost identical with the slope of the curves in Fig. II. They do not, however, show the minimum near 6 ro $\mathrm{m} \mu$, but from $540 \mathrm{~m} \mu$ to about $660 \mathrm{~m} \mu$ are relatively higher than the other curves, while beyond $660 \mathrm{~m} \mu$ they are practically identical, within experimental errors, with the former curves. Comparison of these two sets of curves shows, therefore, that the most noticeable effect of a rain in the atmosphere is to increase the relative transmission in the yellow and orange regions of the spectrum, the maximum relative transmission lying at about $640 \mathrm{~m} \mu$. 
The observations represented by curve $I$, Fig. I2, were made on the night of May 6 and 7 , during which time there was a steady rainfall, as depicted in curve 2, Fig. 13 . Ordinates are rain-gage readings; abscissas are time. The rate of rainfall, derived from these readings, is represented in curve $I$, Fig. I3. These two curves may be associated with curve 3 , which gives the observed transmission at $540 \mathrm{~m} \mu$ during the same interval of time. The

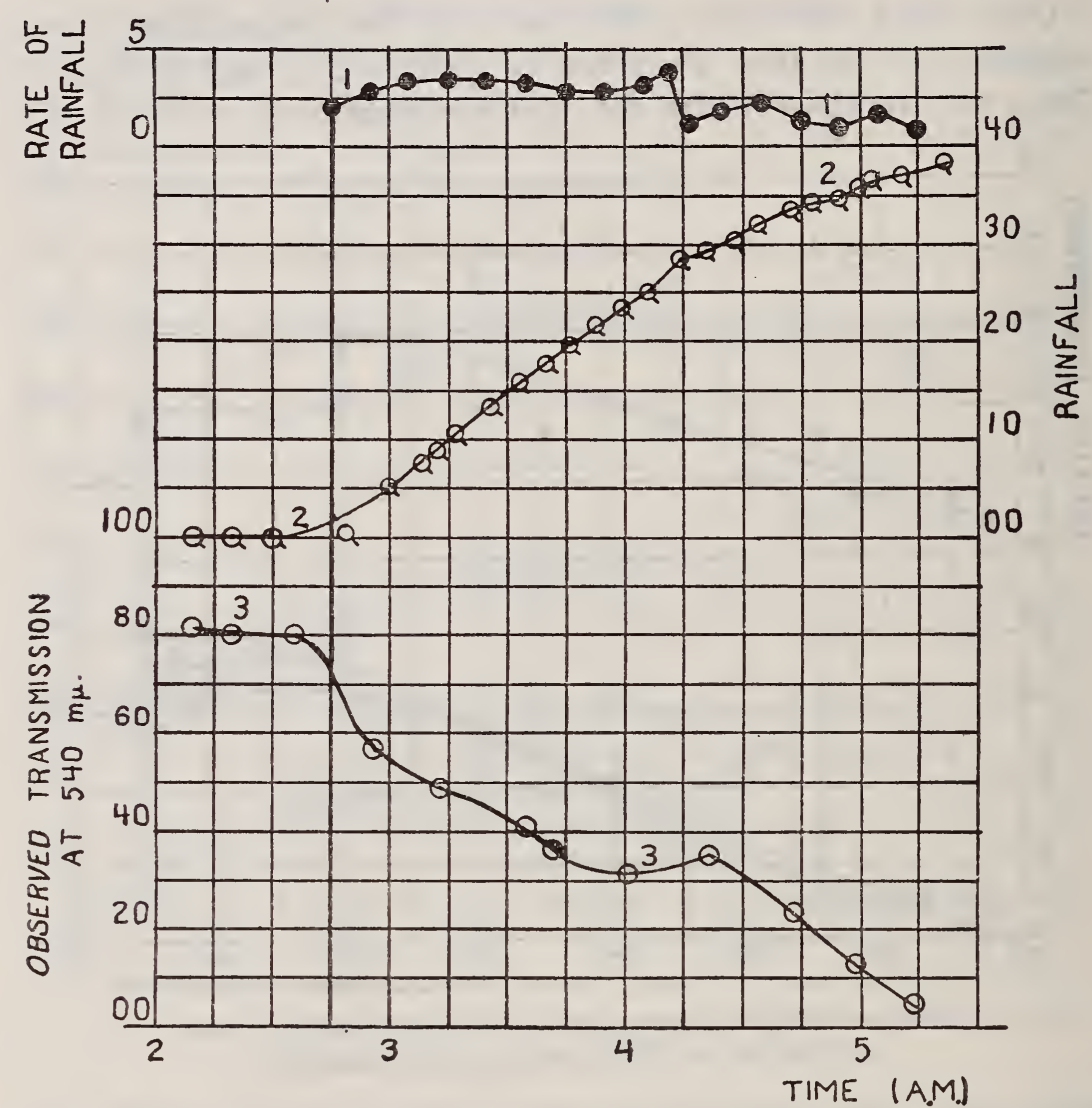

FIG. I3.-Comparison of rainfall and change in observed transmission at $540 \mathrm{m \mu}$ for May 6-7, I9I9

No. I, rate of rainfall; No. 2, rainfall; No. 3, change of observed transmission at $540 \mathrm{~m} \mu$

most striking fact brought out is that the transmission decreases steadily during the interval, even though the rate of rainfall remains practically constant. When the rain ceased there was a moderately thick fog. The effect on the transmission is undoubtedly due to the very fine water particles accumulating in the atmosphere during the rain. That this effect was a result of the suspended water and not due to the nature of the raindrops 
is shown by the fact that when the rate of rainfall had dropped to one-fourth of its former value (at 4:I $5 \mathrm{a} . \mathrm{m}$.), the transmission increased very slightly, but again continued to decrease even after the rate of rainfall dropped to the lower value.

A similar set of curves, obtained from the second run, is given in Fig. I 4 for the observations of May 8 and 9 (curve 3, Fig. I2). While the observations in the blue region were being made, there was a rather unsteady rain. The curve shows again a lower transmission at $540 \mathrm{~m} \mu$ after the rain continued for some time. Further

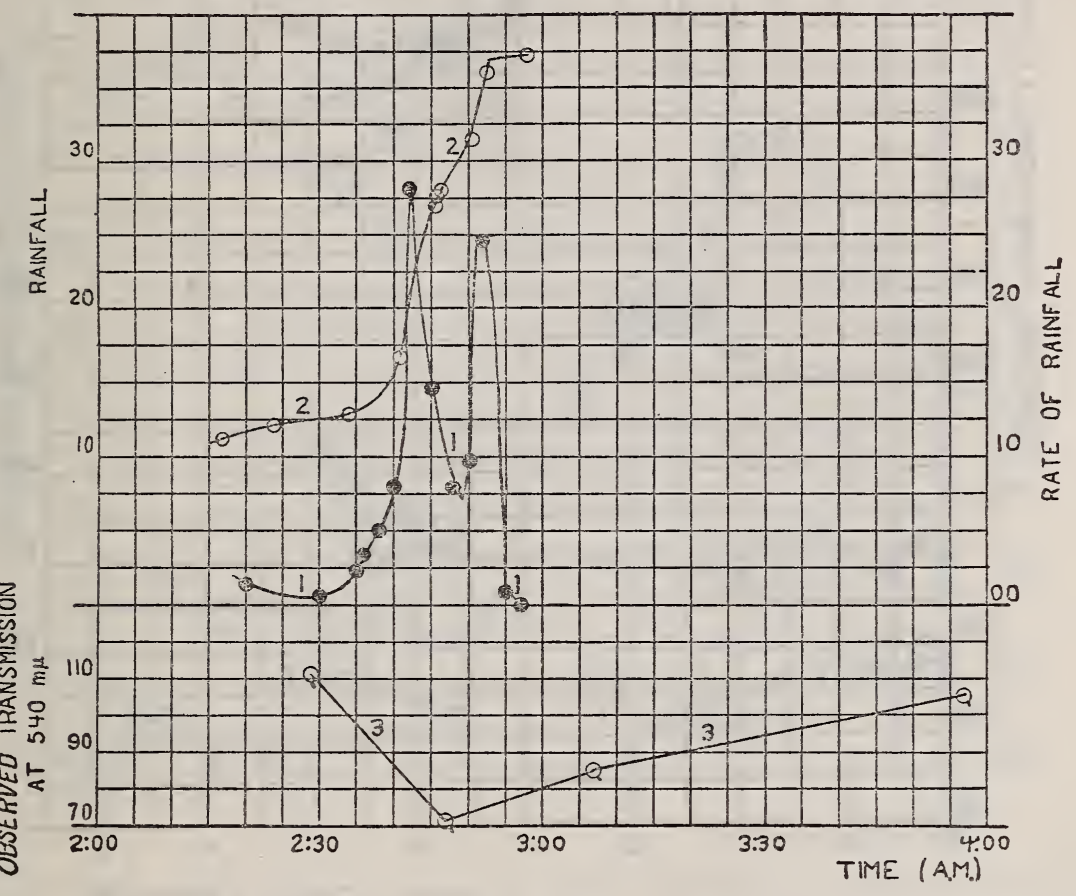

FIG. I4.-Comparison of rainfall and change in observed transmission at $540 \mathrm{m \mu}$ for May 8-9, I9I9, second run

No. I, rate of rainfall; No. 2, rainfall; No. 3 , change of observed transmission at $540 \mathrm{~m} \mu$

conclusion can not be drawn, however, on account of the unsteadiness of the rain combined with the impossibility of making observations at $540 \mathrm{~m} \mu$ at short enough intervals to provide accurate correction values. During the remainder of the run (from $3: 30$ to $4: 30 \mathrm{a}$. m.) there was no actual rainfall, but a rather thick mist which had become a drizzle at the close of the observation.

The observations in curve 2, Fig. I 2, were made during occasional light showers which were too slight for satisfactory reading of the rain gage. In Fig. I 5 are given the curves which show the change in transmission at $540 \mathrm{~m} \mu$ during the time that the observations 
represented by curves $I$ to 8 , Fig. I I, were made. The curves of Fig. I 6 correspond similarly to those of Fig. 12, though these have been given in part in Figs. I3 and I4.

\section{EARIIER RESULTS}

Most of the data obtained with the silvered optical flat are less reliable than those already discussed, because of some uncertainty

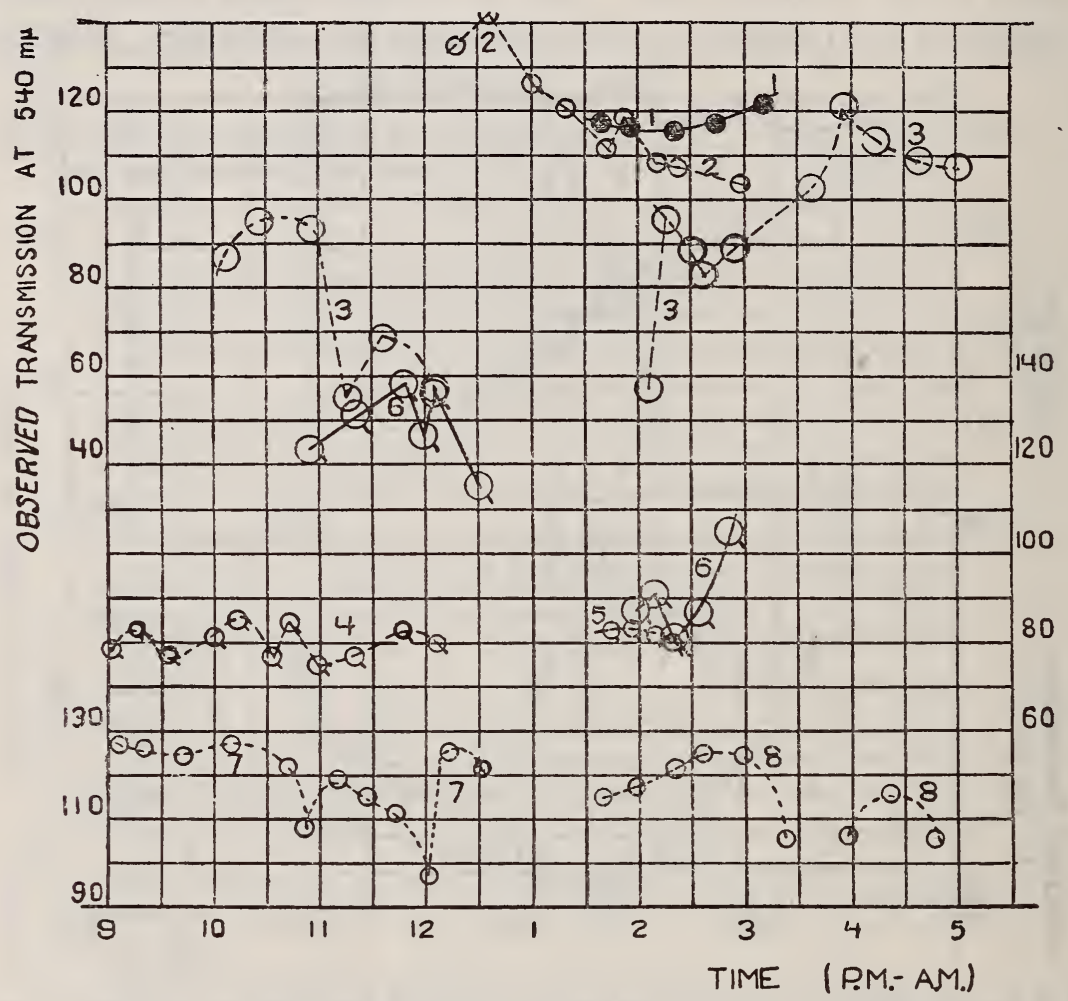

FIG. I5.-Change of observed transmission at $540 \mathrm{m \mu}$ while the observations of Fig. II were being made

No. I, Apr. 28-29; No. 2, Apr. 29-30; No. 3, May 5-6; Nos. 4 and 5 , May 6-7; No. 6, May 7-8; Nos. 7 and 8 , May $12-13$

in the values for the reflecting power due to the tarnishing of the silver surface, and also due to the fact that the mirror was mounted on a wood structure attached to the shed which housed the mirror. Furthermore, certain improvements in the method, miking for greater reliability, had during that time been adopted only in part. The reflecting power of the mirror was determined some time after the observations were made, but on comparing the observations with the data given above, it was found that the reflecting power of 
the slightly tarnished surfaces, as obtained later, was applicable, as was also that for the freshly silvered surface taken from the Smithsonian tables. As already noted, the reflecting power for these conditions is given in curves 2 and 3, Fig. 7 .

The data obtained with the silvered optical flat may also be discussed in groups determined by the weather conditions under which they were obtained. The observations obtained on April 3 and 4 and May I and 2, represented in curves 3 and 4, respec-

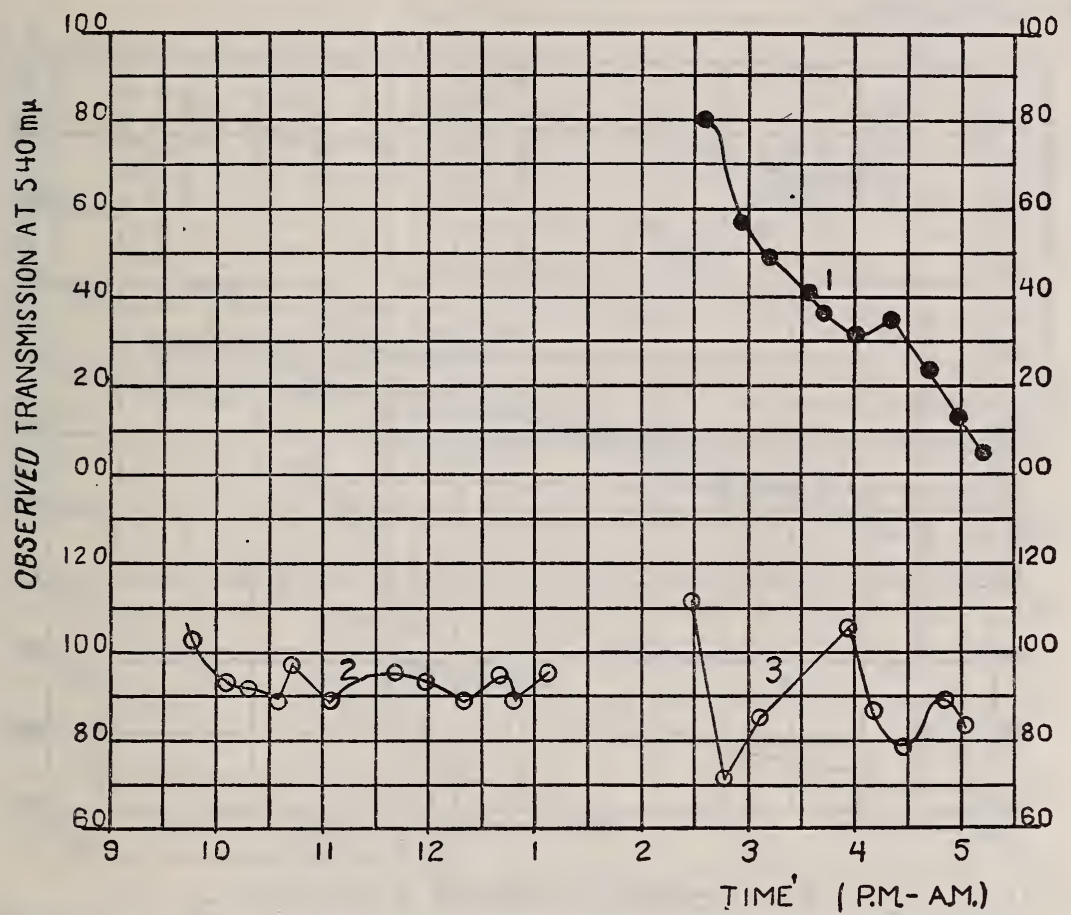

FIG. I6.-Change of observed transmission at $540 \mathrm{~m} \mu$ while the observations for Fig. I2 were being made

No. r, May 6-7; Nos. 2 and 3, May 8-9

tively, of Fig. I7, were obtained under conditions very similar to those designated above as being "generally overcast" and "high humidity;" that is, above 50 per cent. These curves resemble very closely those previously discussed (Fig. II). They possess the two maxima and the more or less decided minimum near 6ro $\mathrm{m} \mu$. Before and after the observations of May I and 2 (curve 4) were made, the atmosphere was misty. The mist on May 2 was too thick to allow measurements to be made. At this time the 500-watt lamp was used and the silver surface of the optical flat 
was fresh. On April 3 and 4 (curve 3 ), the slightly tarnished flat was used. The data in curve $I$, Fig. 17 , are inserted merely because a portion of them were taken during a light snowfall. All observations represented in this curve for wave lengths greater than $540 \mathrm{~m} \mu$ were made through the falling snow. The transmission for wave lengths less than $540 \mathrm{~m} \mu$ dropped very decidedly and regularly. While the mirror moved during the same time, undoubtedly the greater part of this change in transmission was caused by the snowflakes.

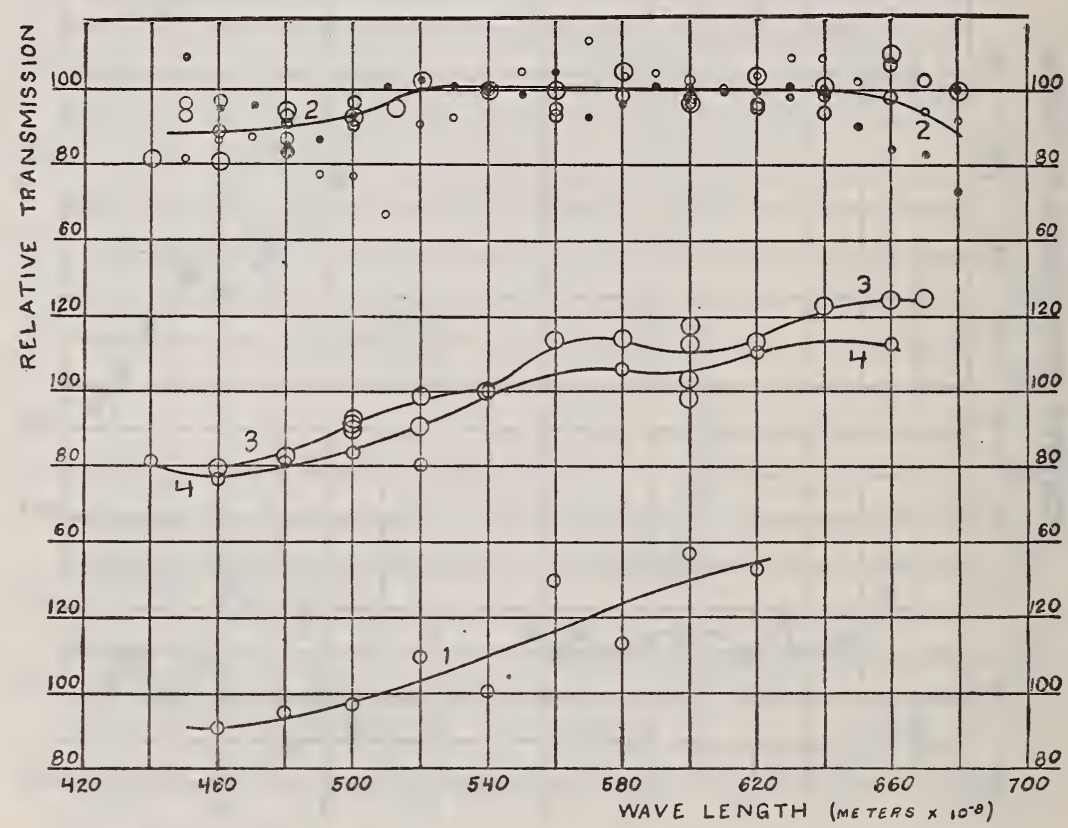

FIG. I7.-Relative transmission of atmosphere

No. I, snow, Mar. 3I-Apr. I; No. 2, clear weather, Apr. I-2 (2 runs), Apr. 2-3, May 2-3; No. 3, generally overcast, Apr. $3-4$; No. 4, generally overcast, May I-2

Curve 2, Fig. I 7 , represents the mean of all the data taken under atmospheric conditions which may be characterized as clear, cold, and of low humidity. On the night of April I and 2 the temperature ranged from +0.4 to $-3.5^{\circ} \mathrm{C}$; on April 2 and 3 , from 4.7 to $3.0^{\circ} \mathrm{C}$. On May 2 and 3 the temperature was $15.5^{\circ} \mathrm{C}$, departing from the general characterization in this respect, but maintaining a low humidity. On April I and 2 there were two complete runs, indicated respectively by dots and small circles. The observations of April 2 and 3 and of May 2 and 3 are indicated respectively by the medium and large circles. From wave length 520 to $660 \mathrm{~m} \mu$ the transmission remains uniform, while for wave lengths greater 
than $660 \mathrm{~m} \mu$ it begins to decrease. Also for wave lengths less than $520 \mathrm{~m} \mu$ the transmission decreases gradually and continuously. There are indications of a slight depression near $480 \mathrm{~m} \mu$. This may be due to a few observations near 450 and $470 \mathrm{~m} \mu$, which seem somewhat erratic. All observations on the above data are corrected for the reflection of the slightly tarnished silvered optical flat. (See curve 3, Fig. 7.) The curves showing changes in

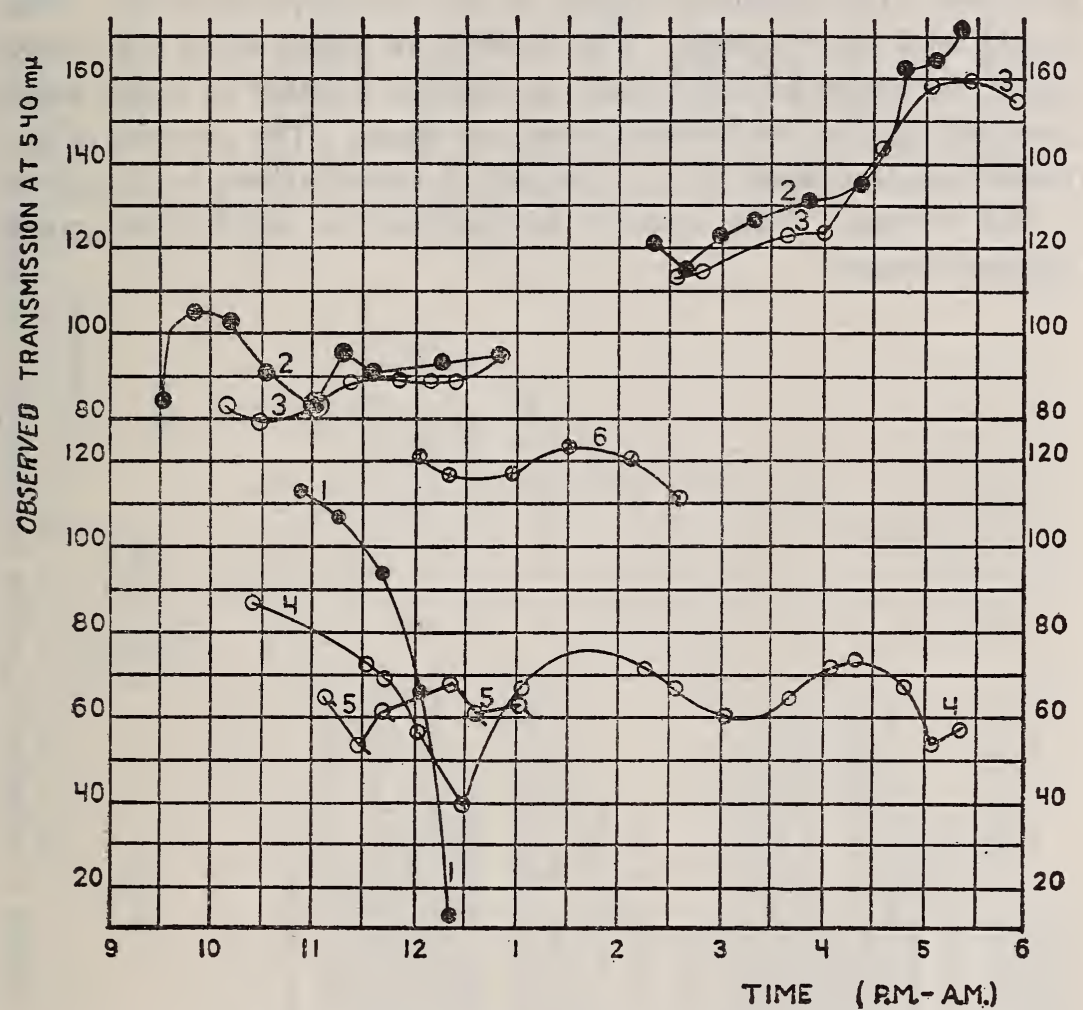

FIG. I8.-Change of observed transmission at $540 \mathrm{m \mu}$ while the observations of Fig. I7 were being made

No. I, Mar. 3I-Apr. I; No. 2, Apr. I-2; No. 3, Apr. 2-3; No. 4, Apr. 3-4; No. 5, May I-2; No. 6, May 2-3

observed transmission at $540 \mathrm{~m} \mu$ during the above observations are given in Fig. Is.

\section{SYNOPSIS OF WEATHER CONDITIONS}

A synopsis of all the observations on, and characterization of, the weather conditions during the time that the observations of the apparent relative transmission were made, is given in Table $\mathrm{I}$. In the various columns are given the number of the figure and the 
number of the curve, the time at which the observations were made, a general description of the weather, the average barometric pressure, the temperature, and the relative humidity; also the absolute humidity obtained by reference to tables, a general characterization of the manner in which the transmission at 540 $\mathrm{m} \mu$ varied, and finally the performance of the whole apparatus. This performance was determined by the test for the position of the image of the mercury lamp in the spectrophotometer, when viewed with an eyepiece. The number of times when the image was in the center of the ocular slit and the number of times when it was off and had to be readjusted are given. The amount of the greatest displacement in any one set of observations is also given in this column. The amount is specified in $\mathrm{m} \mu$ for the green $(546 \mathrm{~m} \mu)$ image. 


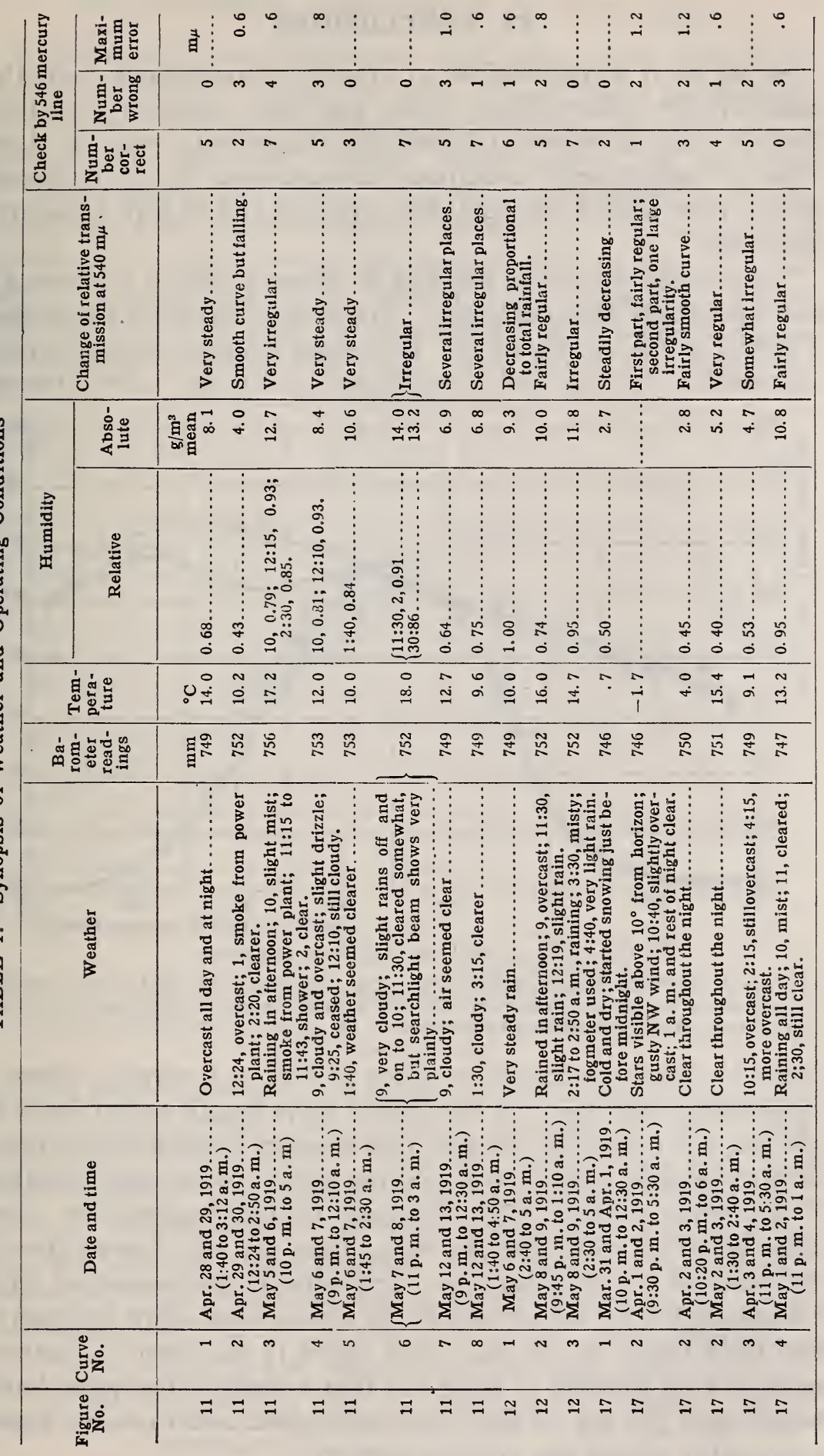




\section{CONCLUSIONS}

So far as it is permissible to draw any conclusions from the relatively few observations made, one may associate the three distinct types of relative transmission respectively with the three types of atmospheric conditions characterized in an indefinite way as clear and of low humidity, overcast and of high humidity, and rainy.

The average curve for the first is shown in Fig. I7 (curve 2), and has already been discussed. The average curve for the second is shown in Fig. I9 (curve $I$ ). It has two maxima, one at $580 \mathrm{~m} \mu$ and one at $650 \mathrm{~m} \mu$, and a minimum at $610 \mathrm{~m} \mu$. The average

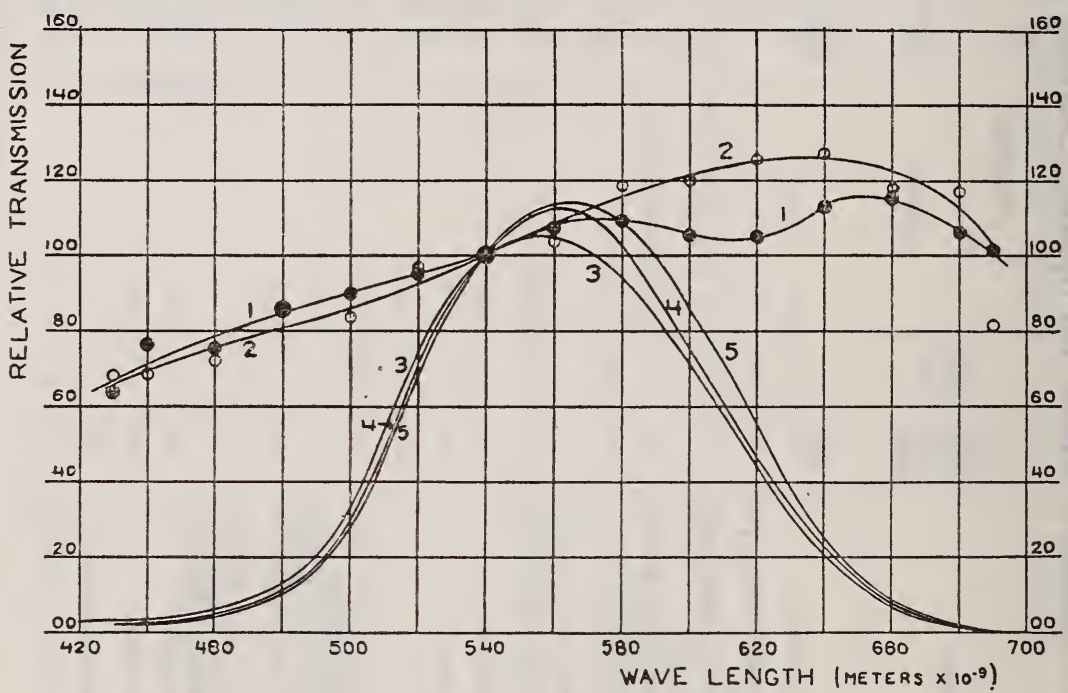

FIG. I9.-Average relative transmission curves

No. I, generally overcast and high humidity (curves of Fig. II and Fig. 17, Nos. 3 and 4); No. 2, generally rainy (curves of Fig. I2); No. 3, relative visibility; No. 4, product of relative visibility and curve No. 1 ; No. 5 , product of relative visibility and curve No. 2

curve for the rainy condition, given in Fig. I9 (curve 2), shows a maximum at $64.0 \mathrm{~m} \mu$. In the shorter wave-length region down to $560 \mathrm{~m} \mu$, the curves for the last two weather conditions are practically identical; from 560 to $660 \mathrm{~m} \mu$ the curve for rainy weather is somewhat higher. The decrease in the transmission that takes place for wave lengths longer than $660 \mathrm{~m} \mu$, irrespective of the state of the weather, may undoubtedly be associated with the absorption by the oxygen of the atmosphere, since its absorption band begins at $687 \mathrm{~m} \mu$ and is about $15 \mathrm{~m} \mu$ broad. Furthermore, it is of interest to point out that a similar absorption band begins near $720 \mathrm{~m} \mu$, so that the transmission could not rise again appreciably within the visible spectrum. 


\section{GENERAL APPLICATION OF THE DATA}

It has already been pointed out ${ }^{9}$ that such data as given above have an important bearing not only on searchlight illumination, but also on the head lamps for automobiles and locomotives, on photography-particularly aerial photography-and on lamps for lighthouses, and the like. It has also been pointed out how a knowledge of the relative spectral transmission of the atmosphere contributes to the answer of the question as to what is the best color for a searchlight beam. To elaborate, for the sake of clearness upon the latter point, let us imagine a light source radiating at the same rate throughout the visible spectrum. Depending

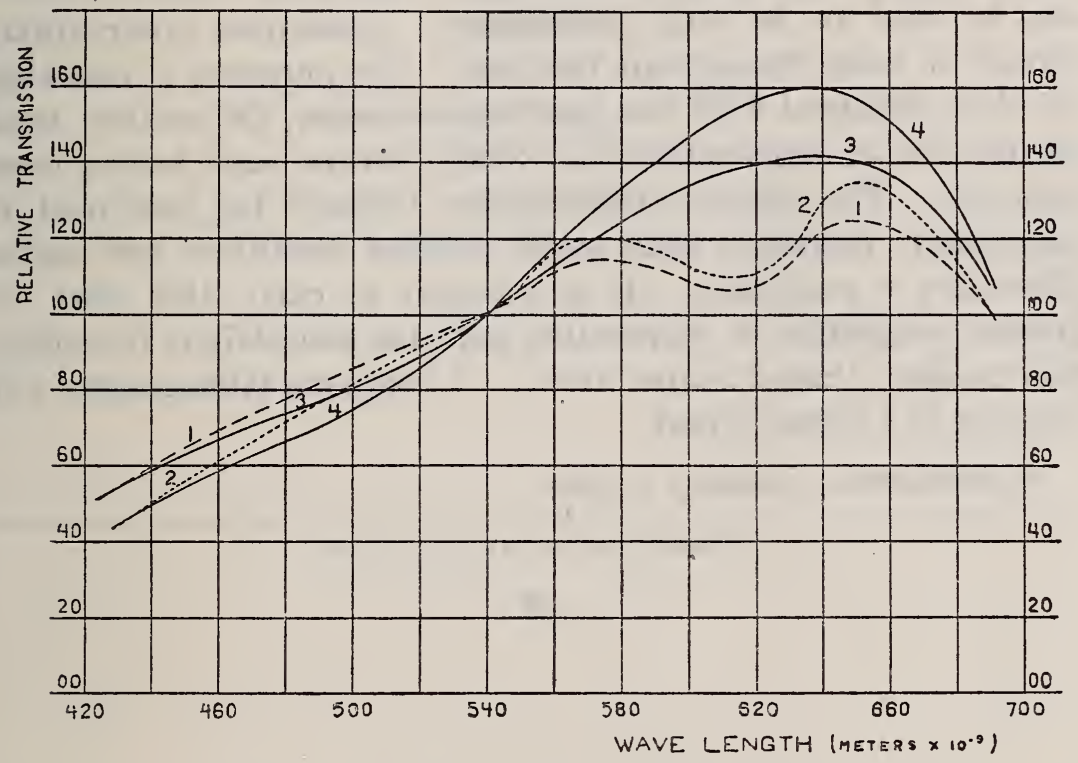

FIG. 20.-Relative transmission at greater distances

No. I, overcast and high humidity, $1800 \mathrm{~m}$; No. 2, overcast and high humidity, $2400 \mathrm{~m}$; No. 3, rainy, I $800 \mathrm{~m}$; No. 4, rainy, $2400 \mathrm{~m}$

upon the state of weather, the energy at some distance away will be distributed through the spectrum according to one of the transmission curves above. When this energy falls upon the retina, the relative distribution of brightness through the spectrum will be in accordance with the relative sensibility of the eye to brightness through the spectrum. The resultant relative distribution of brightness in the spectrum of the source will be given by reducing the former values at the various wave lengths by the relative values of the visibility at the same wave lengths. Such curves are drawn in Fig. 19, depicting the visibility curve 
and the product of the visibility function by the relative transmission factor for two states of the weather, "high humidity" and "rain." The maxima of these curves are at 562 and $565 \mathrm{~m} \mu$, respectively.

It is interesting to compute from the average curves what the relative transmission is for greater distances through the atmosphere. Such curves are given in Fig. 20 for distances of 1800 and $2400 \mathrm{~m}$, for the weather conditions of curves $I$ and 2, Fig. I 9.

It may be pointed out that data bearing on the transmission of light through the atmosphere are absolutely essential for the proper understanding of the principles underlying the use of search lamps and similar illuminants. The work reported above can be said to be only preliminary. Numerous observations should be made throughout the year. For purposes of checking the data obtained with the spectrophotometer, the method used should also be supplemented by others, several such having been indicated. The spectral transmission through fog and mist is particularly desirable, both under outdoor conditions and under laboratory ${ }^{10}$ conditions. It is planned to carry this work to greater completion in coöperation with the Searchlight Investigation Section, United States Army. A complete bibliography will be given in a future report.

WASHINGTON, January I, I920. 